\title{
QUEEN'S
UNIVERSITY
BELFAST
}

\section{The Imagined Contact Hypothesis}

Crisp, R. J., \& Turner, R. N. (2012). The Imagined Contact Hypothesis. Advances in Experimental Social Psychology, 46, 125-182. https://doi.org/10.1016/B978-0-12-394281-4.00003-9

Published in:

Advances in Experimental Social Psychology

Document Version:

Peer reviewed version

Queen's University Belfast - Research Portal:

Link to publication record in Queen's University Belfast Research Portal

Publisher rights

Copyright ( 2012 Elsevier Inc. All rights reserved.

This is the author final version of a work published in Advances in Experimental Social Psychology, volume 46, 2012 here:

http://www.sciencedirect.com/science/article/pii/B9780123942814000039

\section{General rights}

Copyright for the publications made accessible via the Queen's University Belfast Research Portal is retained by the author(s) and / or other copyright owners and it is a condition of accessing these publications that users recognise and abide by the legal requirements associated with these rights.

Take down policy

The Research Portal is Queen's institutional repository that provides access to Queen's research output. Every effort has been made to ensure that content in the Research Portal does not infringe any person's rights, or applicable UK laws. If you discover content in the Research Portal that you believe breaches copyright or violates any law, please contact openaccess@qub.ac.uk. 


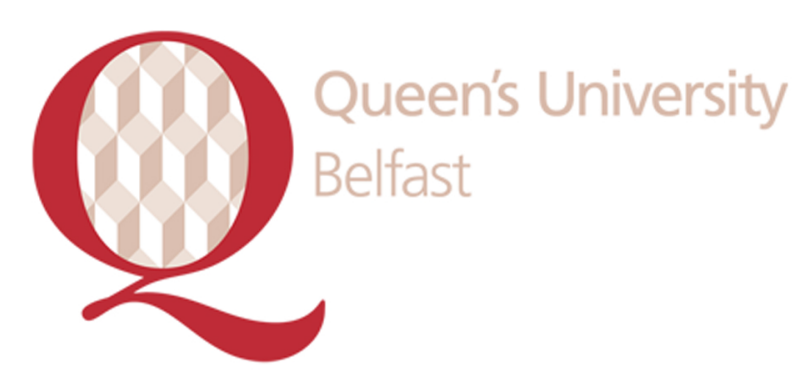

\section{Queen's University Belfast - Research Portal}

\section{The Imagined Contact Hypothesis}

Crisp, R., \& Turner, R. (2012). The Imagined Contact Hypothesis. In Advances in Experimental Social Psychology. (Vol. 46, pp. 125-182). Elsevier. 10.1016/B978-0-12-394281-4.00003-9

\section{Published in:}

Advances in Experimental Social Psychology

\section{Document Version:}

Author final version (often known as postprint)

\section{Link:}

Link to publication record in Queen's University Belfast Research Portal

\section{General rights}

Copyright for the publications made accessible via the Queen's University Belfast Research Portal is retained by the author(s) and / or other copyright owners and it is a condition of accessing these publications that users recognise and abide by the legal requirements associated with these rights.

\section{Take down policy}

The Research Portal is Queen's institutional repository that provides access to Queen's research output. Every effort has been made to ensure that content in the Research Portal does not infringe any person's rights, or applicable UK laws. If you discover content in the Research Portal that you believe breaches copyright or violates any law, please contact openaccess@qub.ac.uk. 
Chapter in press for Advances in Experimental Social Psychology (2012)

\title{
The Imagined Contact Hypothesis
}

\author{
Richard J. Crisp \\ Centre for the Study of Group Processes, University of Kent \\ and \\ Rhiannon N. Turner \\ Institute of Psychological Sciences, University of Leeds
}

Running head: IMAGINED CONTACT

Word count: 19, 318 (text only)

\section{Acknowledgements}

Richard Crisp, Centre for the Study of Group Processes, University of Kent and Rhiannon Turner, Institute for Psychological Sciences, University of Leeds.

We are grateful to Dominic Abrams, Gordon Hodson and Stefania Paolini for their invaluable feedback and comments on an earlier version of this paper.

Correspondence regarding this chapter should be sent to R. J. Crisp at the Centre for the Study of Group Processes, School of Psychology, University of Kent, Canterbury, CT2 7NP, Email: r.crisp@ kent.ac.uk or to R. N. Turner at the Institute for Psychological Sciences, University of Leeds, Leeds, LS2 9JT, Email: r.n.turner@leeds.ac.uk 


\begin{abstract}
Imagined intergroup contact (Crisp \& Turner, 2009) is a new indirect contact strategy for promoting tolerance and more positive intergroup relations. Research has shown that mentally simulating a positive interaction with an outgroup member can elicit more favorable explicit and implicit outgroup attitudes, less stereotyping, and enhance intentions to engage in future contact. This review documents the range of benefits that accrue from imagined contact, the processes through which it operates, and the conditions that limit or enhance its effectiveness. Studies have shown when, how and why imagining contact reduces prejudice against a range of different target groups, and how it can be integrated with existing contact-based approaches to provide maximally effective strategies for improving intergroup relations. The approach is not without its critics, and this review addresses the controversies and debates stimulated by imagined contact theory and research. The review concludes with a discussion of the value that imagery techniques can bring to implementations of contact theory, and how the approach offers a new, flexible and effective tool for practitioners and policy makers in their efforts to promote, encourage and enhance more harmonious intergroup relations.
\end{abstract}

Keywords: IMAGINED CONTACT, INTERGROUP CONTACT, PREJUDICE, DISCRIMINATION, TOLERANCE 


\section{The Imagined Contact Hypothesis}

"[social psychology is] an attempt to understand and explain how the thought, feeling and behavior of individuals are influenced by the actual, imagined, or implied presence of others" (Gordon Allport, 1954a, p. 5; emphasis added).

"since wars begin in the minds of men, it is in the minds of men that the defenses of peace must be constructed" 1945 Moto of the United Nations Educational, Scientific and Cultural Organization

\section{Introduction}

60 years since Gordon Allport's seminal treatise on The Nature of Prejudice (1954b) we now understand psychological processes to be key in the formation, perseverance, and perhaps most importantly, the reduction of prejudice. Central is the contact hypothesis, the proposition that social contact between different groups can, under the right conditions, improve intergroup relations. The hypothesis has generated over 500 studies testing the prejudice-reducing potential of social contact for a wide range of groups, in a wide range of social contexts. We (Crisp \& Turner, 2009) recently proposed a new perspective on intergroup contact, a perspective that provides a powerful addendum to the original hypothesis. The perspective combines accumulated research on contact theory with recent advances in social cognition, and builds on Allport's original assertion that social behavior can be influenced not only by actual experiences, but also the imagined presence of others. Simply put, we proposed that the very concept of contact, mentally articulated in the form of an imagined interaction, could in-and-of itself have a positive impact on intergroup perceptions. This chapter is about this imagined contact hypothesis, and the power and potential it holds for efforts to promote, encourage and enhance more harmonious intergroup relations.

Our research program set out to answer some key questions: Could simply imagining positive contact experiences change how people perceive outgroups? Could such an approach 
provide unique insights into the processes that promote more positive intergroup relations? In so doing could it provide a template for the development of new and effective implementations of contact theory? In this Advances chapter, our aim is to update our 2009 theoretical statement by integrating research that has sought to answer these questions. We therefore provide a refined and elaborated theoretical model that draws on the accumulation of over 25 studies carried out in our laboratories, incorporates the findings from previous reviews, and integrates the contributions of other researchers who have begun testing the hypothesis. As such we intend this chapter to form, in conjunction with our original statement, an inclusive theoretical specification of imagined contact effects, a definitive review of extant empirical work, and a roadmap for future research and implementation.

The chapter is structured thematically in parts that respectively describe the development of imagined contact theory, research and application. We first outline basic principles of mental simulation, providing the a priori case for the assertion that simply imagining contact could change intergroup perceptions. We go on to describe how recent advances in contact theory have laid the foundation for the introduction of these ideas about mental simulation, and how imagined contact represents a logical next step in the evolution of the theory. We then describe in detail the imagined contact hypothesis, and the theoretical model that frames the research we go on to review. As suggested by our title, in preparing this chapter we went back to Allport's early writings on The Nature of Prejudice, with the specific intention of placing imagined contact theory within the context of Allport's original vision for intergroup contact. Notably, there is little reference to the use of imagery in the book, and certainly not in the chapters most commonly cited in relation to intergroup contact. However, delving into some lesser cited chapters reveals how Allport did, in fact, consider the potential use of imagery in establishing 
more positive intergroup relations. These subtle, yet instructive, early thoughts frame our theoretical treatise within the parameters of the original hypothesis, which we explicitly update to incorporate imagined contact's newer notions of mental representation and mental simulation.

We go on to systematically review evidence for the outcomes, mediators and moderators specified by our theoretical model. We discuss how imagined contact facilitates the full range of outcomes relevant to reducing prejudice, including implicit and explicit attitudes, self-efficacy, intentions, approach tendencies and actual behavior. We review studies revealing underlying process, through affective and cognitive pathways, and examine evidence for moderators that operate on these pathways to facilitate or inhibit the impact of imagined contact, distinguishing between those moderators that are task focused and those that are perceiver focused.

In the final part we discuss theoretical implications and practical implementations of the accumulated research on imagined contact. We review studies that have applied imagined contact in real contexts, in particular educational interventions, and we consider the potential use of the approach in zones of intractable conflict. We conclude with a discussion of the current state of theoretical, practical and paradigmatic development of the imagined contact hypothesis. We summarize when it does and doesn't work, the discussions, debates, and critiques that have informed its development, the unanswered questions, and the relationship between three distinct, but related, forms of intergroup contact: imagined, extended and direct. Finally, we discuss the broader outlook for contact theory, how imagined contact research illustrates a resurgent interest in cognitive approaches and how, in so doing, illustrates the power, potential and promise such approaches offer for efforts to improve intergroup relations. 


\section{Principles, Paradigm and Theory}

\subsection{Basic Principles of Mental Simulation}

Since the earliest enquiries (Galton, 1883; James, 1890) our capacity for imaginative thought is a phenomenon that has enjoyed enduring appeal. Could this capacity be harnessed in efforts to reduce prejudice and improve intergroup relations? This basic idea, expressed in our 2009 American Psychologist article, was met in some quarters with skepticism. Were we seriously suggesting that we could 'imagine away' the appalling realities of war, conflict and intergroup discrimination? We proposed that imagery techniques may afford the ability to more flexibly and creatively explore processes underlying intergroup contact effects, and offer a wide range of practical implementations of contact theory that could be applied to educational and organizational contexts (Crisp \& Turner, 2009). Critics retorted that such quintessentially laboratory-based techniques are simply too trivial to tackle deep rooted prejudices, pervasive conflicts, or genocide (Lee \& Jussim, 2010) or that the cursory nature of imagery makes it wholly unrealistic as a solution for attempts to improve intergroup relations (Bigler \& Hughes, 2010).

These critiques represented reasonable reactions to our hypothesis, given the historically predominant focus on more direct (i.e., face-to-face) forms of contact in social psychology. However, one only has to look beyond the boundaries of prejudice research, to the broader psychological sciences, to find it a view out of step with much theory and research on behavior change. A brief survey of these fields finds mental simulation to be a core cognitive process; a critical component of biological and cognitive systems, embedded in theoretical models ranging from mimicry and theory of mind, to the cognitions and emotions that characterize reasoning, self-regulation, planning and goal pursuit. This evidence, which we briefly recount below, asserts 
the importance of mental imagery as a potentially invaluable psychological tool for promoting behavior change.

\subsubsection{Social Inference}

Functional neuroimaging research has shown that mental simulations employ the same neurological mechanisms involved in memory, emotion and motor control (Kosslyn, Ganis, \& Thompson, 2001). These studies have revealed the key role that mental imagery plays in social cognition. For instance, when perceiving another person's behavior, common motor representations are activated to the extent that there is a match between perceived and represented behavior (Preston \& de Waal, 2002), a capacity that allows us to simulate the mental states of others (e.g., intentions, feelings, and beliefs; so-called 'Theory of Mind'; see Goldman, 2005). This work has shown how such simulations constitute a core cognitive process involved in the planning and rehearsal of social interaction (i.e., enabling shared representations between self and other, empathy, and theory of mind).

\subsubsection{Self-Regulation}

Imagination is not only essential for predicting others' mental states, but also in the spontaneous inferences we make about our own attitudes and behaviors. Kahneman and Tversky (1982) identified simulation as a heuristic tool that maintains basic functionality, fulfilling epistemic and self-evaluative needs. The key role that simulation plays in meeting these needs is illustrated in work on counterfactual reasoning, the ability to consider alternative possibilities for past behavior (Galinsky \& Moskowitz, 2000). This imagining of alternative and converse realities - counterfactuals - has been shown to have important consequences for emotions, judgments, and behavior. For instance, upward counterfactual simulations involve the generation of alternatives better than reality (Roese \& Olson, 1997; Sanna, Carter \& Burkley, 2005) and 
serve a self-improvement function, allowing individuals to plan for a better future at the expense of immediate feelings of dissatisfaction. Mental imagery is therefore not just key to understanding others, it is key to the maintenance of self-esteem; to helping us chart a way through the triumphs and tribulations of everyday life. It is a mechanism of self-regulation that enables and empowers our pursuit of ambitions, aims and aspirations.

\subsubsection{Goal Pursuit}

Predicated on its role in helping us infer and understand both others' and our own mental states, mental imagery serves a fundamental function in the selection, rehearsal, preparation and planning of goal-directed behavior. The literature on goal pursuit documents its use as a selfregulatory technique in domains such as planning and decision-making, sports performance, clinical psychology, advertising, health and academic achievement (Taylor, Pham, Rivkin, \& Armor, 1998). This literature shows that mental simulations not only help us understand social inferences about self and others, but also how individuals initiate action to elicit behavioral change. For instance, Ratcliff et al. (1999) directed undergraduate students either to think about the reasons why people should find studying enjoyable (e.g., learn new things, make better grades, boost self-confidence) or to imagine the actions that people might take up to make studying more enjoyable (e.g., create a comfortable atmosphere, study with a friend, reward oneself). Imagining actions elicited more effective and productive study behaviors than did thinking about reasons. Similarly, Sherman and Anderson (1987) attempted to reduce psychotherapy dropout rates at an outpatient clinic using a scripted simulation procedure administered at the intake session. Those who imagined staying in therapy reported both an increased expectancy of staying in therapy and were less likely to subsequently drop out. 
There are many other examples of the use of imagery in domains such as planning and decision-making (Anderson, 1983), sports performance (Feltz \& Landers, 1983), clinical treatment of phobia (Raune, Macleod, \& Holmes, 2005), advertising (Escales \& Luce, 2003), health (Sherman, Cialdini, Schwartzman, \& Reynolds, 1985) and academic achievement (Pham \& Taylor, 1999). This accumulated research demonstrates that our capacity to mentally simulate future events is not just the preserve of daydream and fantastical thinking. It is a core psychological mechanism that is vital to basic motor control and action initiation, it has a pivotal role in social inference, it helps us regulate our own emotional reactions to past and future possible events, and it is a key component needed to effect behavior change in domains ranging from education to sporting performance (for a review see Crisp, Birtel \& Meleady, 2011).

If imagination is a critical cognitive process, central to social perception, planning and goal pursuit, could it not also be an effective tool for changing intergroup attitudes? We argue that given its theoretical significance and applied relevance, there is a strong precedent for the incorporation of mental simulation techniques in interventions designed to effect social and behavioral change - even (and especially) in tackling pervasive issues like prejudice. It was this basic idea that led us to consider the application of these principles of mental imagery to research on intergroup contact.

\subsection{A Brief History of Intergroup Contact}

In 1954, Gordon W. Allport published a comprehensive account of the phenomenon of prejudice, from its roots, to its expression, to the means through which it might be reduced. One of the most influential aspects of the book was a chapter entitled The Effect of Contact in which he considered the impact of (de)segregation on the attitudes and beliefs communities hold of one 
another. His observations led to the simple, yet powerful idea that promoting contact between different social groups holds the key to creating more harmonious intergroup relations.

More than half a century after its publication, The Nature of Prejudice is the most widely cited work on prejudice, and remains an inspiration to contemporary prejudice researchers (e.g., Dovidio, Glick, \& Rudman, 2005). In the intervening years since its publication this contact hypothesis has become one of the most extensively researched ideas in psychology (Oskamp \& Jones, 2000) and it provided a framework which researchers still use today. A recent metaanalysis of 515 studies has confirmed Allport's core proposition: There is a robust, highly significant, negative relationship between contact and prejudice (Pettigrew \& Tropp, 2006). Key principles of contact have been distilled into intergroup contact theory (Brown \& Hewstone, 2005; Pettigrew, 1998) which specifies how, when and why contact is associated with reduced prejudice. Contact theory has become a sophisticated account of the conditions under which intergroup interactions have benefits for intergroup relations (for a collection of papers documenting recent advances, see Hodson \& Hewstone, in press).

Having dealt with the question of whether contact reduces prejudice, researchers have, in the past decade, moved on to examine whether there are different types of contact, or different ways in which contact can be applied, to improve intergroup relations. Some of this research has focused on the benefits of face-to-face contact. There is now, for example, extensive evidence that cross-group friendships are particularly effective at reducing prejudice. This research shows that contact works via a range of affective mediating processes including reduced anxiety, and self-disclosure and trust (Levin, van Laar, \& Sidanius, 2003; Hodson, Harry, \& Mitchell, 2009; Paolini, Hewstone, Cairns, \& Voci, 2004; Page-Gould, Mendoza-Denton, \& Tropp, 2008; Pettigrew, 1997, 1998; Turner \& Feddes, in press; Turner, Hewstone, \& Voci, 2007a; Turner, 
Hewstone, Voci, Paolini, \& Christ, 2007b). However, this research has also uncovered one apparent limitation of contact: It is reliant on there being opportunities to engage in contact. For instance, Wagner, van Dick, Pettigrew and Christ (2003) investigated the relationship between cross-group friendships and outgroup attitudes towards foreigners in Eastern and Western Germany. They found that being from East Germany (where there were 1.9\% foreigners) rather than West Germany (where there were 9.7\% foreigners) was associated with less opportunity for contact (fewer foreign neighbors or classmates) and fewer cross-group friends. Accordingly, prejudice was higher among Germans from the East than among Germans from the West.

The fact that direct relations are often difficult to establish led some researchers to seek other, indirect ways of reaping the benefits of contact. Of particular note here is Wright, Aron, McLaughlin-Volpe, and Ropp's (1997) extended contact hypothesis which argues that the benefits associated with cross-group friendship might also stem from vicarious experiences of friendship, the knowledge that ingroup members have friends in the outgroup. If an outgroup member is observed being friendly and positive to ingroup members, expectations about intergroup interactions may become more positive. Similarly, seeing an ingroup member showing tolerance towards the outgroup may influence the attitudes of other ingroup members by setting up the norm for the appropriate behavior towards outgroup members. Initial studies confirmed that individuals who learned about a positive experience between an ingroup and an outgroup member subsequently developed more positive outgroup attitudes (Wright et al., 1997; Studies 3 and 4). A number of cross-sectional (e.g., Paolini et al., 2004; Tausch, Hewstone, Schmidt, Hughes, \& Cairns, 2011; Turner et al., 2007b; Turner, Hewstone, Voci, \& Vonofakou, 2008; Wright, et al., 1997, Studies 1 \& 2) and longitudinal (Feddes, Noack, \& Rutland, 2009) 
studies have subsequently shown that participants who know ingroup members with outgroup friends tend to have more positive outgroup attitudes.

Research on extended contact was important because it showed that direct experience of contact with outgroups is not the only way that contact could have benefits for intergroup relations. Extended contact may be especially useful where there is less opportunity for contact because it does not depend on personal experience, but simply the existence of some contact somewhere in one's social network. The importance of this idea for policy makers and educators seeking to develop interventions to reduce prejudice cannot be understated because it suggests that contact may be a far more powerful and flexible means of improving intergroup relations than previously thought. But one of the limitations of extended contact is that while it goes some way towards solving the opportunity-for-contact problem, it cannot do so entirely. Under some circumstances extended contact could suffer the same limitation as actual contact. In highly segregated settings, or where there is an embedded history of conflict and discrimination, one simply might not know anyone who has an outgroup friend (or even anyone who would interact in any meaningful way with an outgroup member). We could call this a lack of 'extended opportunities' for contact, where no outgroup friends exist within one's wider social network. This is a characteristic of many real contexts of conflict ranging from the Middle East, to Cyprus to the former Yugoslavia.

Nonetheless, research on extended contact was important in the development of the imagined contact hypothesis because it made a critical assertion: Direct experience of contact with outgroups is not a necessary component of contact interventions. Given this basic premise, could then we push the boundaries of the contact concept a little further still? If the mere 
knowledge of others' contact was sufficient to improve attitudes, could simply imagining contact with an outgroup member could be sufficient to change intergroup attitudes?

\subsection{The Imagined Contact Hypothesis}

\subsubsection{Allport's Legacy}

As noted above, much of contemporary contact theory emanates from Allport's (1954b) book The Nature of Prejudice, and in particular a chapter titled "The Effect of Contact". This chapter contains no mention of imagery or simulation techniques. However, in a lesser cited chapter titled "Evaluation of Programs", Allport considered the effectiveness of existing prejudice-reduction programs, particularly those used in schools. Preempting the recent focus on extended contact, he explicitly distinguished between direct approaches to prejudice-reduction, for example those involving acquaintance with the outgroup, such as community projects, with indirect approaches to prejudice-reduction, for example the 'informational approach', learning about the outgroup either through lessons, or the 'vicarious experience approach' involving fictional scenarios such as films, novels, and dramas about the other group. However, he went even further than this and made some observations that have direct relevance to the potential use of imagery in such programs. In comparing the difference approaches, Allport had the following to say:

Some evidence indicates that films, novels, dramas may be effective, presumably because they induce identification with minority group members. There is indication that this approach may be, for certain children, more effective than the informational [imparting knowledge by lectures and text book teaching] or project [working for community projects] approach. If this finding stands up to future research, we shall be confronted with an interesting possibility. It may be 
that strategies of realistic discussion constitute too strong a threat to some people. A milder invitation to identification at the fantasy level may be a more effective first step [italics added]. Perhaps in the future we shall decide that intercultural programs should start with fiction, drama, and films, and move gradually into more realistic methods of training (Allport, 1954b, p. 453).

This reasoning showed impressive foresight, predicting the recent theoretical and empirical developments in the intergroup contact literature in several important ways. Allport foresaw the distinction between direct and indirect interventions which has developed in the past two decades. More pertinent to the focus of this chapter, however, is Allport's recognition of a 'fantasy level' of intervention, and the idea that different forms of intervention may fall on a continuum, varying in terms of how 'realistic' they are. At one end of the continuum are interventions based on mental imagery. These, he argued, might be milder and less threatening than direct interventions, and might therefore provide an effective first step in the fight against prejudice. At the other end of the continuum are realistic methods, which might involve interaction with members of another group. Allport believed that only once the concept of contact had been introduced, and the perceived threat from the outgroup lessened, should more concrete types of intervention be introduced.

These early writings show that Allport himself recognized the potential value in embracing mental imagery in efforts to reduce prejudice, particularly when direct forms of contact could constitute a threat to individuals acclimatized to years of disharmony, and particularly as the first step in programmatic interventions that progressively introduce contact in imagined, vicarious and then direct forms (issues that have very much characterized the development of imagined contact research, as we discuss below). 


\subsubsection{From Rationale To Realization}

Our research on imagined contact can be seen as a direct descendent of Allport's (1954b) early thinking about "fantasy level" contact. Our initial idea was that imagined contact may be valuable as a substitute for contact where actual contact is impossible or unlikely, for example where there are a lack of opportunities to meet people from other groups. We have come, however, to see it as primarily a way of preparing people for future contact. Thus, as Allport envisaged, where contact is possible, but where groups avoid contact because of anxiety, uncertainty and negative stereotypes, imagined contact may be a valuable pre-contact tool. In other words, imagined contact may be a way of preparing people for actual contact, getting them ready to engage with outgroups with a positive and open mind - and a way of mitigating the potential for things 'to go wrong' with real contact under sub-optimal conditions. As such, we frame our description and discussion of imagined contact effects within this basic idea: That imagination is a first step, a way promoting a positive contact mindset, and a way of preparing people to engage positively in future intergroup contact.

We have defined imagined intergroup contact as "the mental simulation of a social interaction with a member or members of an outgroup category" (Crisp \& Turner, 2009, p.234). Our basic hypothesis is that mentally simulating a positive contact experience will create a mental contact 'script', alongside more positive feelings about outgroups, that will result in more favorable outgroup perceptions and enhanced intentions to engage in future contact. The approach has both intuitive and practical appeal. As Allport himself noted, an intervention that involves encouraging participants to identify with another group at the "fantasy" level should, compared to more "realistic" approaches, be "milder", and associated with lower levels of threat. It may therefore be "a more effective first step", which should be followed, gradually, by 
increasingly realistic interventions (Allport, 1954b, p. 543). In addition to these potential benefits, imagined contact is inexpensive, takes only a few minutes to carry out, does not require the complex organization associated with physically bringing together members of different social groups, and can be used where physical contact would be very difficult to achieve (e.g. where there are even a lack of 'extended' opportunities for contact).

Since this initial proposition we have developed, on the basis of theoretical and empirical work, a more detailed model of the antecedents, processes and outcomes of imagined contact. This integrated model can be found in Figure 1. Working back through the model, we argue that there are several key outcomes which are components of progressively more positive intergroup relations. These outcomes begin with attitudes towards the outgroup. Changing attitudes are an important step to promote behavior change, because they increase the likelihood that participants will have more positive behavioral tendencies regarding the outgroup; that is, people who like another group will be more interested in approaching and getting to know members of that group (e.g., Tam, Hewstone, Kenworthy, \& Cairns, 2009). There is also evidence that implicit intergroup attitudes predict non-verbal behavior (McConnell \& Liebold, 2001), which may affect how comfortable and successful intergroup encounters are. Other outcomes examined in this chapter, which bring people closer to intergroup contact, include self-efficacy and behavioral intentions, both of which have been found to be proximal predictors of behavior in other domains (e.g., Bandura, 1986). We also examine the effect of imagined contact on one of the most proximal forms of intergroup behavior, non-verbal behavior directed towards the outgroup. Having established the impact of imagined contact on relevant outcomes we consider evidence for underlying process. There are both affective (anxiety) and cognitive (behavioral script) pathways through which imagined contact exerts its effects. We also consider evidence 
for moderators of imagined contact effects, which we divide into those that are task focused (elaboration, perceptual focus, perspective taken, and typicality) and perceiver focused (prior contact, majority/minority status, and ingroup identification).

\subsection{Basic Task}

While much contact theory research is correlational in nature, the imagined contact paradigm brings to the area a quintessentially experimental approach. Our empirical program has employed techniques and theoretical perspectives from across social cognition and intergroup relations to provide a unique, integrated implementation of the contact hypothesis. The basic imagined contact task we have developed incorporates two critical components: Simulation and a Positive Tone. The prototypic version of the task instruction asks participants the following:

We would like you to take a minute to imagine yourself meeting [an outgroup] stranger for the first time. Imagine that the interaction is positive, relaxed and comfortable.

We have found that engaging in simulation - that is, running through the mental script of an interaction - is critical for observing positive effects. In contrast, thinking of just an outgroup member in the absence of any simulated interaction has no positive effects on attitudes, and in fact can exacerbate bias (see Turner, Crisp, \& Lambert, 2007a; Experiment 2). Positivity is also key. We know that direct contact is more effective at reducing prejudice when it is positive in tone. Numerous studies show that quality of contact is particularly important if contact is to benefit intergroup relations (e.g., Eller \& Abrams, 2004; Islam \& Hewstone, 1993; Stathi \& Crisp, 2010; Voci \& Hewstone, 2003; for a review see Brown \& Hewstone, 2005). The same is true for imagined contact. Empirically we have shown that imagined contact works better when it is positive compared to neutral (Stathi \& Crisp, 2008; Experiment 1; West, Holmes, \& 
Hewstone, 2011 Experiments 3 \& 4). A positive tone is also important to guard against a possible negative tone, which might emerge if participants were left to engage in contact with no direction at all (which may be likely, especially in contexts of conflict or extreme segregation).

Other than these core elements we have found other embellishments to have little impact on the basic effect. However, this is not to say that changing the instructional set has no impact on the effectiveness of imagined contact. On the contrary, the paradigm lends itself to the exploration of task variants that can have specific impacts on specific outcomes. However, these variations tend to be more substantive changes that build on psychological theory and research. We discuss these theoretically-informed (task-focused) modifications to the paradigm in more detail later in this chapter.

Control conditions are also critical to experimental investigations using the imagined contact paradigm. We have typically used a form of the following in order to create a pleasant scene (akin to a positive interaction), but with no reference to groups:

We would like you to take a minute to imagine an outdoor scene. Try to imagine aspects of the scene (e.g., is it a beach, a forest, are there trees, hills, what's on the horizon).

Mindful that this might not control for more generalized positive effects of social interaction per se, we have also used versions simulating positive social interaction with a nonrelevant group (i.e., a positive interaction with a non-relevant stranger versus a positive interaction with a relevant stranger, Stathi \& Crisp, 2008, Expt. 2; Turner \& West, in press; Turner, West \& Christie, in press), for example:

We would like you to take a minute to imagine yourself meeting a stranger for the first time. Imagine that the interaction is positive, relaxed and comfortable. 
Using non-group relevant simulations rule out positive affect arising from generalized social interaction as an explanation for imagined contact effects. In all conditions, participants are given exactly one minute to imagine the scene. To reinforce the instructions we then typically asked participants to write several lines describing the scenario they imagined. This also serves as a valuable manipulation check that participants have been willing and able to generate a positive contact scenario.

\section{Outcomes}

The model presented above specifies positive impacts of imagined contact on a range of outcomes, all of which help prepare people for positive future encounters with the outgroup. We here examine these outcomes in turn. Our initial research established the effect of imagined contact with a member of an outgroup on attitudes towards that group in general. More recent research has considered the effect of imagined contact on behavioral tendencies and behavior itself. In this section we consider research that has shown imagined contact to improve outcomes ranging from those that are more distal to those that are more proximal, on an envisaged 'road to reducing prejudice'. In other words, we focus on the range of outcomes relevant to improving intergroup relations, not just intergroup attitudes (the latter being one component of the range of relevant outcomes). As such, we review the effects of imagined contact on explicit and implicit attitudes, as well as perceptions of confidence and self-efficacy relating to intergroup encounters. We can characterize these outcomes as promoting tolerance, orienting perceivers to think positively about outgroups, but not necessarily stimulating intentions to engage more positively with the outgroup. In the second half of this section we consider outcomes that take people beyond mere tolerance of outgroups to the promotion of engagement, by enhancing intentions to 
seek out future contact, eliciting approach tendencies, through to actual behaviors directed towards the outgroup.

\subsection{Promoting Tolerance}

\subsubsection{Explicit Attitudes}

In our initial test of the imagined contact hypothesis, we conducted a series of studies in which participants were asked to imagine encountering an outgroup member before reporting their attitude towards the outgroup in general (Turner et al., 2007a; see Table 1). In Experiment 1, young participants were either asked to take a minute to imagine meeting an older adult for the first time, or to imagine an outdoor scene. After listing the things they had imagined, they were told that the researchers would be running a second study in a care home in which young people would have the choice of interacting with either an older adult or another young person. They were then asked to indicate their preference for each type of interaction. It emerged that whereas participants in the control condition were more likely to prefer to interact with a young person than with an older person, those who had first imagined contact were equally happy to interact with a young person or an older person; in other words, intergroup bias was significantly reduced by imagined contact. In Experiment 2, we replicated this effect, but using a control condition in which participants simply thought about older adults. Finally, in Experiment 3, we examined the effect of imagined contact on attitudes towards a different group, gay men. Male undergraduate students who had identified themselves as being straight were either asked to spend five minutes imagining talking to a gay man on a train, while learning some interesting and unexpected things about him, or in a control condition, to imagine a hiking trip. Participants were then asked to evaluate gay men in general (for example, did they feel positive or negative, warm or hostile, and suspicious or trusting towards them?), and to indicate how much variability there is among gay 
men (e.g., 'When you think about gay men, do you perceive them as similar to one another?', "Among gay men there are different types of people"; 7-point semantic differential scale). As expected, straight men who imagined a positive encounter with a gay man subsequently evaluated gay men more positively, and perceived there to be greater variability among gay men, compared to a control group.

In subsequent studies, we have shown that imagined contact can improve explicit attitudinal evaluations of a range of outgroups, including Mexicans' attitudes towards Mestizos in Mexico (Stathi \& Crisp, 2008), non-Muslims attitudes towards Muslims (Husnu \& Crisp, 2010a, Experiment 2; Turner \& Crisp, 2010b, Experiment 1; Turner \& West, in press, Experiment 2), illegal immigrants (Harwood, Paolini, Joyce, Rubin, \& Arroyo, 2010) and British teenagers' attitudes towards asylum seekers (Turner et al., in press, Experiment 1). Moreover, imagined contact can even generate more positive affective and cognitive attitudes towards highly stigmatized outgroups that are perceived as physically threatening, such as people with schizophrenia (West et al., 2011).

Notably, Stathi and Crisp (2008) tested whether imagined contact leads not only to improved evaluations of outgroups, but also via greater projection of positive traits from the self to the outgroup. Projection is an important process because it involves the attribution of traits to others and can constitute a fundamental "cognitive basis for ingroup favoritism" (Robbins \& Krueger, 2005, p.42). This is because projection of positive self traits to similar others (i.e., the ingroup) is generally stronger for ingroups than outgroups (Clement \& Krueger, 2002). Establishing that imagined contact not only improves outgroup attitudes, but also contributory processes and related constructs, is important for developing an inclusive account of impacts on outcomes relevant to reducing prejudice. To this end, we next turn to studies that have shown 
imagined contact to improve attitudes and evaluations not only on the explicit level, but also at the implicit level.

\subsubsection{Implicit Attitudes}

Whereas explicit attitudes are conscious, deliberative and controllable (and are usually captured by traditional self-report measures), implicit attitudes are unintentionally activated by the mere presence (actual or symbolic) of an attitude object, and, as noted above, are therefore less likely to be influenced by social desirability or demand characteristics than are explicit measures. Showing an impact on implicit attitudes is also important because while explicit attitudes are associated with deliberative behaviors, implicit measures are associated with more subtle, indirect and spontaneous non-verbal behaviors (e.g., McConnell \& Leibold, 2001). These behaviors associated with implicit attitudes are the subtle bastions of prejudice, maintaining biases in even overtly egalitarian societies. Of equal importance, if imagined contact can reduce negative non-verbal behavior, it may help to produce smoother, more successful face-to-face encounters with outgroup members in the future.

In Experiment 1, undergraduate participants were either asked to imagine an interesting and unexpected encounter with an older adult, or in a control condition, an outdoor scene (Turner \& Crisp, 2010b). In both conditions, participants were given two minutes for the imagination task, before being asked to write down what they had imagined. As a measure of implicit intergroup bias we used the implicit association test (IAT, Greenwald, McGhee, \& Schwartz, 1998). We used a young-old version of the IAT, in which participants were required to simultaneously categorize target stimuli (typical young names like Brad, Zack, and Lucy, and typical old names such as Cyril, Arthur, and Mildred) and attribute stimuli (positive words like smile, and paradise, and negative words like slime and pain) which appeared one at a time on the 
computer screen (see Turner et al., 2007b for a detailed description of this IAT). We expected that young participants would show faster reaction times when required to sort young names and positive words with one key, and old names and negative words with the other, than when required to sort young names and negative words with one key and old names and positive words with the other. In line with predictions, participants in the imagined contact condition showed more positive explicit attitudes towards older adults than participants in the control condition. Most importantly, on the implicit measure, participants in the imagined contact condition were less biased towards the category young over the category old than participants in the control condition, see Table 2 .

In a second experiment, participants were asked to either imagine a relaxed, positive and comfortable encounter with a Muslim, or to simply think about Muslims. We used a Muslim non Muslim version of the IAT, which was identical to the measure used in Experiment 1, except that typical young and old names were replaced with typical British Muslim names (e.g., Mohammed, Fatima, Yusra) and British non-Muslim names (for this we used biblical names, e.g., Matthew, Luke, Eve). Again, participants who imagined contact with a Muslim were less biased than participants in the control condition who simply thought about Muslims. Indeed, whereas participants in the control condition showed implicit ingroup-favoring bias, this bias was eliminated in the imagined contact condition and participants actually became outgroup favoring, see Table 2 .

These findings are important for three reasons. First, we have argued that imagined contact should not only promote more positive evaluations of outgroups, but also a greater interest in, and positive inclination toward, engaging in intergroup contact (Crisp \& Turner, 2009). The fact that, in Experiment 2, there was an implicit outgroup favoring bias in the 
imagined contact conditions suggest that, for a short time, imagined contact may promote a greater preference for outgroupers (and outgroup contact) than for ingroupers, as a positive contact norm becomes temporarily hyper-accessible.

Second, although explicit attitudes are associated with deliberative behaviors, implicit measures are associated with more subtle, indirect and spontaneous non-verbal behaviors (e.g., McConnell \& Leibold, 2001). If imagined contact can reduce instances of negative non-verbal behavior, it may help to produce smoother, more successful face-to-face encounters with outgroup members in the future. Recent work has replicated and extended our understanding of this positive impact of imagined contact on implicit attitudes with school children (Vezzali, Capozza, Giovannini, \& Stathi, in press-a).

Third, demonstrating an impact of imagined contact on implicit measures helps to rule out a demand characteristics explanation for the effects. It is possible, for instance, that participants responded more positively in the imagined contact conditions because they guessed the rationale of the experiment and behaved in accordance with the perceived expectations of the experimenter. Although we typically find few participants guess the specific aims of these studies (particularly when more complex and between-subjects designs are used), any study that employs explicit measures runs the risk that participants may manipulate their responses to fit perceived aims (or indeed to purposely not conform to them). In contrast, implicit attitudes are unintentionally activated by the mere presence (actual or symbolic) of an attitude object, and are less likely to be influenced by demand than are explicit measures. The studies reported above by Turner and Crisp (2010b) and Vezzali et al. (in press-a) therefore help rule out any demand explanation for the effects. We also note that other studies reviewed later in this chapter offer alternative ways of ruling out demand effects, such as the use of non-verbal behavioral measures 
(Turner \& West, in press) and taking dependent measures one day after the imagery session (Husnu \& Crisp, 2010b).

Research on changing attitudes can be seen as important for intergroup relations in and of itself (indeed it is the focus of many contact studies). However, in our imagined contact model we regard explicit and implicit attitudes as important because they are one of a specific set of outcomes associated with preparing people for greater contact in the future. Tackling negative attitudes about the outgroup is one part of that process, but it is also important to change people's attitudes about themselves. Specifically, part of getting people to think more positively about outgroup contact is changing their beliefs about their own capacity to behave appropriately and confidently in these (challenging) situations. As such, as well as attitudes, we have also focused on outcomes associated with enhancing how people feel about the prospect of intergroup contact.

\subsubsection{Self-Efficacy}

While imagined contact helps to improve intergroup attitudes and evaluations, a key determinant in preparing people for action is self-efficacy. In other words, increasing confidence in one's ability to interact effectively with outgroup members (e.g., without inadvertently displaying behaviors that could be construed as prejudiced). Bandura's theory of social cognitive learning (1986), which recognized the critical role played by self-efficacy in people's behavior, provides some theoretical grounding for our use of this measure in the contact domain, with a measure of "contact self-efficacy" (Stathi, Crisp \& Hogg, 2011, p. 276). According to Bandura's theory, self-efficacy regulates human functioning via cognitive, affective and motivational processes. Bandura defined self-efficacy as a person's belief that she or he can effectively perform "courses of action required to deal with prospective situations containing many ambiguous, unpredictable, and often stressful elements" (Bandura \& Schunk, 1981, p.587). 
Therefore, self-efficacy, or the confidence that a person has in performing a behavior, is a crucial determinant of people's willingness to engage in a specific behavior. If people are not confident that they will achieve desired outcomes, they have limited incentives to act (Bandura, 2001). Enhancing contact self-efficacy would therefore yield considerable benefits for intergroup relations.

Several studies in the wider literature on behavior change have demonstrated that mental simulation techniques can also increase self-efficacy. Landau, Libkuman and Wildman (2002) found that participants who imagined themselves lifting a heavy object were subsequently more likely to believe that they could lift heavier weights. Similarly, Jones et al. (2002) found imagery to impact on levels of self-efficacy in female novice climbers. Feltz and Riessinger (1990) found that participants who underwent an imagery program reported higher performance expectations, and actually performed better, on a muscular endurance task.

Stathi et al. (2011) therefore expected the mental simulation of contact experiences to raise contact self-efficacy. In Experiment 1, contact self-efficacy was measured by adapting Gudykunst and Nishida's (1986) measure of attributional confidence. The scale included nine items measuring confidence about interactions with British Muslims (1 strongly disagree, 7 strongly agree). For example: "When I interact with British Muslims" ... "I am confident in my ability to predict their attitude" and "I am confident in my ability to predict their willingness to communicate". Experiment 1 showed that mentally simulated contact can act as a preparatory measure for real intergroup interactions by increasing contact self-efficacy. In Experiments 2 and 3, contact self-efficacy was measured using a modified version of Fan and Mak's (1998) measure of social self-efficacy. This is a measure that targets self-efficacy in an interactive conversational context; we therefore considered it more pertinent to contact situations than the 
scale used in Study 1. The scale consisted of six items (1 strong disagree, 7 strongly agree). Participants were asked to think of interactions they might have with British Muslims in the future and indicate their agreement with statements such as: "I would feel confident talking to British Muslims" and "I would feel I have common topics for conversation with British Muslims”. Imagining contact was again found to enhance contact self-efficacy.

These studies demonstrated that as well as changing attitudes, imagining contact can increase people's confidence in dealing with intergroup contact situations when they occur. Enhancing self-efficacy is an important part of the process of orienting people more positively to outgroup contact, promoting tolerance in the sense that when people find themselves in an outgroup contact situation, they feel confident in acting appropriately (and without bias). However, feeling that one can behave appropriately in a contact situation is not the same as actively seeking out contact, and specifically seeking to engage positively with outgroups. Understanding if, and how, imagined contact can elicit more approach-focused outcomes will be important if we are to encourage people to engage in face-to-face contact voluntarily, enthusiastically, and with an open mind. It is to these types of outcome that we turn next.

\subsection{Approach-focused Outcomes}

\subsubsection{Intentions}

The studies reviewed above show that imagined contact can improve attitudes, and make people more confident about their abilities to engage in contact with outgroup members should the situation arise. However, could imagined contact also encourage people to actively seek out more contact with the outgroup? We have argued that this is an important component of any intervention seeking to promote more positive intergroup relations (Crisp, Husnu, Meleady, 
Stathi, \& Turner, 2010). To answer this question we explored the impact of imagined contact on intentions to engage in future contact.

There are some good a priori reasons for expecting imagery to encourage intention, again by looking across the broader psychological sciences. For instance, Ratcliff et al. (1999) directed undergraduate students either to think about the reasons why people should find studying enjoyable (e.g., learn new things, make better grades, boost self-confidence) or to imagine the actions that people might take up to make studying more enjoyable (e.g., create a comfortable atmosphere, study with a friend, reward oneself). Imagining actions elicited more positive behavioral intentions toward studying than did thinking about reasons. In a study using similar methodology, Ten Eyck et al. (2006) found that simulation enhanced intentions to a greater extent than did thinking about reasons for a range of beneficial activities (e.g., dieting, studying, and exercising).

Husnu and Crisp (2010a) provided an initial test of the hypothesis that imagined contact can enhance intentions to engage in future contact. British non-Muslim undergraduate students were asked to imagine contact with a British Muslim, or were allocated to a control condition. In order to measure intentions to engage in future contact, participants were asked to respond to four items. These were adapted from Ratcliff et al.'s (1999) measure of behavioral intentions. Participants were asked questions such as "How much do you intend to interact with British Muslims in the future?" (1= not at all, to $9=$ very $m u c h)$, "How much time do you think you might spend learning about Islam in the future?" $(1=$ none at all, to $9=$ a lot of time $)$, and "How willing would you be to attend a mosque gathering to learn more about Islamic beliefs and practices?" ( $1=$ not at all willing, to $9=$ very willing $)$. On this composite measure of intentions, participants who imagined contact subsequently reported greater intentions to engage in future 
actual contact than did participants in the control condition. Subsequent studies have confirmed that enhanced intentions to engage in future contact are a robust approach-focused outcome arising from imagined contact (Crisp \& Husnu, 2010; Husnu \& Crisp, 2010a; 2010b, Expt. 2; Vezzali, Capozza, Stathi, \& Giovannini, in press- $b$; for a review focused on this outcome, see Crisp et al., 2010).

\subsubsection{Behavioral Approach Tendencies}

An important step in any preparation for face-to-face contact is to see whether it results in a greater tendency to approach, rather than avoid, the outgroup. In other words, does imagined contact make people more open to the idea of interacting with outgroup members? In an earlier study, we found that following imagined contact, participants showed a reverse of the ingroup bias effect that is normally observed; that is, participants showed an implicit preference for the outgroup over the ingroup, rather than the reverse (Turner \& Crisp, 2010b). This indicates that imagined contact might, for a short time at least, promote approach orientations related to outgroup members, and potentially for contact with those individuals.

In order to directly test this hypothesis, Turner et al. (in press, Experiment 1) asked British high school students either to imagine interacting with an asylum seeker or, in a control condition, to imagine interacting with an unspecified stranger. In both conditions, participants were then asked to spend two minutes imagining a positive interaction with this individual, before writing down what they had imagined. Next, participants' behavioral approach tendencies were measured (Mackie, Devos, \& Smith, 2000). They were asked to indicate the extent to which, when thinking of asylum seekers, they wanted to 'talk to them', 'find out more about them', and 'spend time with them'. As expected, participants in the imagined contact condition showed a stronger tendency to approach the outgroup than participants in the control condition. 
We believe that imagined contact should help to prepare people for direct contact by not only eliminating negative, but also generating positive, expectations (Crisp \& Turner, 2009). Experiment 2 therefore included a measure of tendencies to avoid the outgroup. In order to investigate whether the findings generalized to a different intergroup context, a different participant group (university students) and a different target outgroup (gay people) were used. Forty one undergraduate students who identified themselves as straight were randomly assigned to either imagine an interaction with a gay person or, in the control condition, with a stranger. To measure avoidance behavioral tendencies, participants were asked to indicate the extent to which, when thinking of gay people, they wanted to "avoid them", "keep them at a distance" and "have nothing to do with them". Participants in the imagined contact condition reported a greater desire to approach the outgroup and a reduced desire to avoid the outgroup, see Figure 2.

\subsubsection{Non-Verbal Behavior}

The research described above shows that imagined contact can promote intentions to engage in future contact, and behavioral tendencies reflecting those intention. Are these intentions and tendencies translated into actual behavior? We know from the broader literature on mental simulation that such strategies can have a direct impact on actual behavior, ranging from interview performance (Knudstrup, Segrest \& Hurley, 2003) to academic study (Rivkin \& Taylor, 1999) to sporting performance (Feltz \& Landers, 1983). There are therefore good reasons to expect imagined contact to result in more positive behaviors directed to the outgroup.

One's non-verbal behaviors relating to outgroups are particularly important for fostering more positive intergroup relations, and are likely to have the greatest impact on the success of the intergroup encounter (Dovidio, Hebl, Richeson, \& Shelton, 2006). Past research has shown that whereas people tend to be successful at controlling explicit behavior, such as the verbal 
content of their speech in order to behave in a pleasant manner, they struggle to hide anxiety, which tends to be displayed through non-verbal behavior (Shelton \& Richeson, 2005).

Unfortunately, it is this non-verbal behavior that tends to affect the perceptions of the interaction partner, leading them to believe that they are disliked (Dovidio et al., 2006). This could potentially have profound negative implications for the effectiveness of direct contact.

Imagined contact may help prepare people for intergroup contact by altering these subtle, non-verbal behaviors towards the outgroup. Following imagined contact, participants should be perceived as more friendly by an outgroup interaction partner as a result of their more positive non-verbal behavior. Research on interpersonal relations suggests that positive behavior during dyadic interactions tends to be reciprocated. For example, people like, and trust, those who like and trust them (Petty \& Mirels, 1981). Thus, the interaction partner would be likely to respond to the participant in a friendly manner, resulting in a more pleasant intergroup encounter.

Turner and West (in press) conducted two studies to examine whether imagined contact would affect a simple assessment of non-verbal behavior towards stigmatized groups. In Experiment 1, we asked undergraduate students who reported being of normal weight to imagine having a positive encounter with either an obese person (imagined contact condition) or a stranger (control condition). After completing the imagination task, all participants were told that, as part of a second study, they would now be meeting with an obese individual to discuss how obesity is perceived in today's society. The experimenter took each participant to a room, which was locked, with the lights off, and a stack of chairs in the corner. Upon entering the room, and turning on the light, the experimenter said: 'I'm just going to get Emily who you'll be chatting to, do you mind grabbing a couple of chairs for the two of you? I'll be back in a minute". While they were waiting, participants were given a short questionnaire to complete to 
provide demographic information, to indicate what they thought the aim of the study was, and to indicate whether were at all suspicious about the purposes of the study. No participant indicated any suspicion of the hypotheses of the study. Finally, the experimenter re-entered the room and explained to the participant that the experiment had ended. Unbeknownst to the participant, the final measure of intergroup attitudes was a behavioral measure: the distance the participant placed between the two chairs in centimeters, measured after the participant left. Participants in the imagined contact condition placed the chairs closer together (40 $\mathrm{cm}$ on average) than those in the control condition (50 cm on average; see Table 3). A second experiment was carried out in order to see whether the effect of imagined contact on behavior would generalize to a second stigmatized group, Muslims. We also included explicit measures of feelings and beliefs about the outgroup. Undergraduate students who identified themselves as not being Muslim were either asked to imagine meeting a Muslim person or a stranger. They were subsequently told that they would be having a short interaction with a Muslim participant, 'Ayesha', to discuss Islamophobia in the UK. Compared to participants in the control condition, those in the imagined contact condition reported more positive beliefs regarding the character traits held by the typical Muslim, had more positive feelings about Muslims and behaved more positively towards the outgroup, choosing to sit closer to their outgroup interaction partner, see Figure 3.

\section{Underlying Processes}

So far we have reviewed research demonstrating positive impacts of imagined contact on a range of outcomes relevant to improving intergroup relations. These outcomes include not only those that indicate more tolerance (implicit and explicit attitudes, self-efficacy), but also those that show imagined contact to stimulate a desire to engage more positively with the outgroup (intentions, action tendencies, non-verbal behaviors) In this section we review evidence for the 
mechanisms that explain why imagined contact has these beneficial impacts. We specify two related underlying processes: Affective and cognitive.

\subsection{Affective Processes}

Research on intergroup contact theory has tended to focus more on affective than cognitive processes, revealing a clear and consistent mediating role for direct contact effects. Most notably, Pettigrew and Tropp's (2006) meta-analysis demonstrated that the most powerful processes underlying contact effects were affective, with intergroup anxiety emerging as particularly important. It is reasonable, therefore, to expect imagined contact effects to operate through a similar affective mechanism.

\subsubsection{Anxiety}

Intergroup anxiety is the negative emotional reaction that can occur at the prospect of having to engage in an intergroup encounter. It is most likely to arise where there has been minimal previous contact, and can arise as a consequence of negative expectations of rejection or discrimination during cross-group interactions, or fears that the interaction partner, or the respondents themselves, may behave in an incompetent or offensive manner (Stephan \& Stephan, 1985). These fears may lead people to avoid intergroup contact altogether (Plant \& Devine, 2003; Shelton \& Richeson, 2005). However, even when contact is initiated there is considerable evidence that anxiety can impede the success of intergroup encounters (Dovidio et al., 2006; Hebl, Tickle, \& Heatherton, 2000). For example, while people tend to be effective at monitoring and controlling their explicit attitudes and verbal behaviors, they are less skilled at monitoring and controlling affective reactions, which may "leak out" through nonverbal channels (Dovidio et al., 2006). 
In contrast, successful intergroup contact reduces intergroup anxiety, a process which is commonly associated with reduction in prejudice (Voci \& Hewstone, 2003; Islam \& Hewstone, 1993; Pettigrew \& Tropp, 2006; Paolini et al., 2004; Turner et al., 2007b). The challenge here is clear. Since intergroup anxiety can lead to avoidance of direct contact (Plant \& Devine, 2003; Stephan \& Stephan, 1985) people, especially in highly segregated or conflicting areas, cannot benefit from the positive effects of contact until levels of anxiety are reduced. Earlier, we showed how imagined contact can help to prepare people for direct contact by increasing selfefficacy about one's ability to operate effectively contact settings, generating more positive intentions regarding intergroup contact, increasing people's tendency to approach (rather than avoid) the outgroup, and even reducing social distance when anticipating an actual encounter with an outgroup member. One of the ways in which imagined contact might have some of these benefits is because it reduces intergroup anxiety.

In an initial study investigating the role of anxiety, straight male participants were asked to imagine a positive interaction with a gay man (Turner et al., 2007a, Experiment 3). As noted earlier, participants who spent a few minutes imagining intergroup contact subsequently had a more positive attitude towards gay men in general. In addition to measuring attitudes, however, we also included a measure of intergroup anxiety. Specifically, we asked participants whether the thought of a direct encounter with a gay man made them feel, amongst other things, awkward and uncomfortable. We found that the positive relationship between imagined contact and outgroup attitude was mediated by reduced intergroup anxiety, see Figure 4.

We also have more direct evidence to show that, by reducing anxiety, imagined contact might increase one's desire to approach the outgroup. Turner et al. (in press) found that the effect of imagined contact with gay people on tendency to approach gay people in general was 
mediated in part by reduced intergroup anxiety. Examining a different target outgroup, Husnu and Crisp (2010a, Experiment 3) found among undergraduate students that the effect of imagined contact on outgroup attitudes, and subsequent intentions to engage in contact with older adults, was also mediated by reduced intergroup anxiety.

Convergent evidence for the role of anxiety in imagined contact effects can be found in studies showing some negative impacts of imagery. Stathi and Crisp (2008) found that a positive tone was critical in order for imagined contact to yield a positive impact. West et al. (2011) built on this finding to show that on of the reasons why a positive tone is important is because without it imagined contact could increase anxiety. West et al. tested imagined contact with a negatively stereotyped group, people with schizophrenia, who are generally perceived as dangerous and unpredictable (Angermeyer \& Matschinger, 2005; Schulze, Richter-Werling, Matschinger, \& Angermeyer, 2003). They found that when participants were simply asked to imagine contact (i.e., without specifying that the imagined interaction should be positive), the task actually increased intergroup anxiety. This makes sense - when outgroups are characterized by negative stereotypes, simply asking participants to imagined contact is unlikely to yield benefits. Participants will draw upon the most accessible information they have about the outgroup, their existing negative stereotype, which will increase intergroup anxiety. Like direct forms of contact, imagined contact must be presented in a positive way in order to promote more positive outgroup attitudes. Correspondingly, in a third experiment, West and colleagues found that imagining a positive encounter with someone with schizohprenia did enhance positive attitudes towards people with schizophrenia, and this effect was mediated by reduced intergroup anxiety (in line with the anixety mediation demonstrated by Turner et al., 2007 and Husnu \& Crisp, 2010a). These studies therefore offer converging evidence of the key role that anxiety plays in imagined 
contact effects, but also underscore the importance of ensuring perceivers imagine a positive outgroup interaction when implementing imagined contact, particularly where an outgroup is highly stigmatized and perceived as threatening.

\subsubsection{Trust}

A second affective mediator that has recently been identified as a process underlying imagined contact is outgroup trust. This can be broadly defined as a positive expectation about the intentions and behavior of an outgroup towards the ingroup (Lewicki, McAllister, \& Bies, 1998). Consequences of trust include enhanced cooperation, information sharing, and improved communication and problem solving, all of which are likely to contribute towards successful relations between members of different groups (Hayashi, Ostrom, Walker, \& Yamagishi, 1999). Outgroup trust is also a necessary part of reconciliation strategies that aim to improve community relations in the aftermath of intergroup conflicts. This is because it allows individuals to accept the risk of being vulnerable and to make conciliatory initiatives to the other party with some degree of assurance that they will not be exploited (Blackstock, 2001; Dovidio, Gaertner, Kawakami, \& Hodson, 2002). If people believe that the outgroup can be trusted, they will be more willing to engage in contact with them.

Turner et al (in press) tested whether trust would change behavioral tendencies directed towards the outgroup. In Experiment 1, imagined contact with an asylum seeker resulted in an approach orientation towards asylum seekers. To assess trust, participants had been asked to indicate their agreement with the following statements: "I would be able to trust an asylum seeker stranger as much as any other stranger" and "I would be able to trust an asylum seeker with personal information about myself". As expected, participants in the imagined contact condition trusted asylum seekers more and had a more positive attitude towards asylum seekers 
than participants in the control condition. Moreover, path analysis showed that outgroup trust and outgroup attitude mediated the relationship between imagined contact and approach orientation.

In a second experiment, in which imagined contact with a gay person increased approach orientation and reduced avoid orientation towards gay people in general, the role of trust, attitude, and this time, intergroup anxiety, were examined. Participants in the imagined contact condition reported greater trust, more positive attitudes and less anxiety towards gay people than those in the control condition. Path analysis revealed that imagined contact predicted less intergroup anxiety and more positive outgroup attitudes, and greater outgroup trust. In turn, less intergroup anxiety predicted a stronger tendency to approach the outgroup, more trust predicted a reduced tendency to avoid the outgroup, and a more positive outgroup attitude predict both a greater tendency to approach the outgroup and a reduced tendency to avoid it, see Figure 5.

The importance of trust as positive emotion elicited by imagining contact has received further support from a study by Vezzali et al. (in press-b) in which they show trust to mediate not only enhanced future contact intentions but also increased attribution of uniquely human emotions to immigrant groups (reduced infrahumanization; see also Brambilla, Ravenna, \& Hewstone, in press). These findings, that imagined contact increases trust, are important because trust is considered to be a more demanding gauge of intergroup relations than positive evaluation. This is because it represents a potential risk to the ingroup in a way that holding positive outgroup attitudes does not (Tam et al., 2009). Specifically, to trust someone, one must accept the risk of being vulnerable and to attain some degree of assurance that they will not be exploited (Blackstock, 2001; Dovidio et al., 2002). The fact that imagined contact results in more 
outgroup trust suggests that it may form an important component of effective prejudice-reduction interventions.

\subsection{Cognitive Processes}

While anxiety demonstrably has a key role to play in establishing positive imagined contact effects, we also believe there is a correspondingly critical role for cognition. In particular, one might ask why should imagined contact reduce anxiety at the prospect of intergroup contact? We believe that imagined contact provides perceivers with a positive mental script for what to expect in future encounters, and it is this that provides the cognitive basis for the reduced anxiety about future outgroup contact (and sows the seeds for more positive emotions like trust and forgiveness).

There are good theoretical and empirical reasons for believing script availability to be a core cognitive component of the imagined contact effect. Studies of the use of mental imagery in a wide range of domains have principally invoked the notion of such scripts to explain observed effects. A mental script is the cognitive representation of a sequence of behaviors (Schank \& Abelson, 1977). The idea is that when an individual imagines a scenario in which they perform a particular action, a behavioral script will be formed and stored in memory. Once a script has been formed and activated (through imagery) it can influence one's expectations, intentions, and interpretations of immediate events, as well as one's behavior in the situation (Anderson, 1983). Subsequently, when the individual is asked to make a judgment about intention, or perform the behavior, the script will be available for use (Anderson, 1983; Anderson \& Godfrey, 1987; see also Carroll, 1978). These ideas are based on the availability heuristic (Tversky \& Kahneman, 1973), which describes the ease with which one can "bring to mind" a psychological concept, whether it be an event, issue, person or object (Sherman \& Anderson, 1987). This work shows 
that a wide range of judgments and beliefs are influenced by the cognitive availability of relevant information (e.g., Ross, Lepper, \& Hubbard, 1975). Correspondingly research has confirmed that once a behavioral script has been formed (through imagining the scenario) it influences one's expectations and intentions because it is a cognitively available source of diagnostic knowledge that can be used to make the judgment about one's own intentions (Anderson, 1983; see also Gregory, Cialdini, \& Carpenter, 1982; Wilson \& Capitman, 1982).

Just as people have scripts for a wide range of everyday scenarios (queuing, parking, eating in a restaurant) we have argued that they can have intergroup contact scripts (Crisp et al., 2010; Husnu \& Crisp, 2010a). Furthermore, these contact scripts can be based on imagined, as well as actual, encounters. Behavioral scripts may be an important part of how imagined contact works because they provide the mental constructs that enable more positive affective construals (i.e., reduced anxiety). Evidence for the cognitive script component of imagined contact effects can be found in a review of studies that have explored moderating conditions; in particular, studies that have tested whether the strength of the cognitive script formed by imagined contact varies in theoretically predictable ways. We therefore now turn to consider studies that have examined these moderating conditions.

\section{Moderating Conditions}

Understanding the moderating conditions under which imagined contact exerts positive effects is critical for implementation, as these moderators delineate the optimal conditions under which imagined contact interventions should be introduced to perceivers. Importantly, however, moderators also provide some important indications about the processes underlying imagined contact effects (through a moderation-of-process approach; Spencer, Zanna, \& Fong, 2005), in particular relating to script availability. The research described in this section is therefore also 
instructive for developing our understanding of underlying processes. Below, we divide moderators in to two broad types: task-focused (based on modifications to the imagined contact task itself) and perceiver-focused (based on perceiver characteristics or experiences).

\subsection{Task-Focused Moderators}

Research has shown that theory-driven changes to the way the imagined contact task instructions are delivered can have a significant effect on its impact. We consider four taskfocused moderators: elaboration, perceptual focus, perspective taken, and typicality.

\subsubsection{Elaboration}

Husnu and Crisp (2010a) modified the basic imagined contact instruction to by asking participants to imagine an elaborated contact scenario, a kind of "assisted" imagery task. Participants assigned to the elaborated imagined contact condition received the following modified instructions:

I would like you to take a minute to imagine yourself meeting a

British Muslim for the first time. While imaging this think specifically of when (e.g. next Thursday) and where (e.g. the bus stop) this conversation might occur. During the conversation imagine you find out some interesting and unexpected things about the stranger.

As well as the potential practical benefits of strengthening the effects of the imagined contact task, modifying the task in this way also enabled a test of the proposed underlying script availability mechanism. The reason why elaborated imagined contact should enhance intentions was derived from research showing that when we make more detailed plans, this provides an available behavioral script that can provide the cognitive roadmap for future behaviors (Gollwitzer, 1993). Husnu and Crisp (2010a) hypothesized that elaborated imagined contact 
would create a more vividly represented (and therefore available) behavioral contact script, and in turn this would enhance future contact intentions. The elaborated instructions should therefore have a greater impact on intentions because they help participants to create a more cue-rich simulation that makes the imagined behavior subsequently more available at the judgmental phase (Anderson, 1983; Gregory et al., 1982; Wilson \& Capitman, 1982).

In one study, Husnu and Crisp (2011; Experiment 2) assessed the impact of this sort of assisted imagery on likelihood estimates of future contact. Undergraduate participants were asked: "How many elderly people do you know now?" and "How many elderly people do you think you might know in 5 years time?". We reasoned that if assisted imagery helps create a more vivid, cue-rich script upon which to draw when making likelihood estimates, then these participants would predict having more outgroup friends in the future. The findings revealed no difference between simple and elaborated imagined contact task instructions for the number of outgroup members known now. However, in five years time participants estimated that they would have a higher number of outgroup acquaintances in the elaborated imagined contact condition compared to the simple imagined contact condition, see Figure 6.

In another study, Husnu and Crisp (2010a; Experiment 1) randomly allocated British nonMuslim undergraduates to either an imagined contact or elaborated imagined contact condition. Again, we hypothesized that having a more vivid, cue-rich scenario on which to draw would influence subsequent judgments about intended behavior. The study revealed that significantly greater intentions to engage in future contact were reported by participants in the elaborated imagined contact condition compared to the standard imagined contact condition.

Husnu and Crisp (2010a) not only experimentally manipulated the nature of the imagined contact task in a way that should theoretically produce effects consistent with the proposed script 
mechanism, but also measured vividness of the imagined scenario. Vividness has been a key focus of research on mental imagery (Marks, 1999). It is defined as "a combination of clarity and liveliness. The more vivid an image, therefore, the closer it approximates an actual percept" (Marks, 1972, p. 83) and, according to McKelvie (1995), vivid visual imagery has characteristics resembling the real scenario in that it is generally clear, bright, sharp, detailed and lively. It has been argued that anything that enhances the vividness of the imagined scenario should lead to stronger intentions because it is indicative of a concrete, cue-rich, and therefore available behavioral script (Anderson, 1983). As such, the vividness of the imagined scenario is a good indication of how available the formed script will be when participants come to make judgments about behavioral intention.

In order to measure the vividness of the imagined scenarios participants were asked the degree to which the image was: faint-vivid; fuzzy-clear; dim-bright; vague-sharp; dull-lively; simple-detailed on bipolar scales ranging from 1 to 9 . To measure intentions to engage in future contact participants were asked to complete Ratcliff et al.'s (1999) measure of behavioral intentions. The study revealed not only significantly greater intentions to engage in future contact, but also that participants in the elaboration condition reported that the scenario they imagined was significantly more vivid. Mediational analysis revealed that this greater vividness predicted intentions while controlling for imagined contact, see Figure 7. The findings support the notion that creating a vivid, cue-rich contact scenario is an important cognitive process through which imagined contact exerts its positive impact (see Crisp et al., 2010).

\subsubsection{Perceptual Focus}

Husnu and Crisp (2010b) examined a more basic means of enhancing vividness and the effectiveness of the imagined contact task, closing one's eyes. Closing one's eyes has been found 
to enhance the vividness of mental imagery ability in neuroimaging studies (Marx et al., 2003; 2004) and has been associated with greater subjectively reported vividness of imagined scenarios (Narchal \& Broota, 1988). It should therefore provide a simple, straightforward boost to the efficacy of imagined contact, consistent with the proposed script availability mechanism. Husnu and Crisp (2011; Experiment 1) asked participants to imagine contact with an elderly stranger or a control task with their eyes either shut or open. Intentions to engage in future contact were significantly greater in the imagined contact / eyes closed condition than the imagined contact / eyes open condition. In contrast, in the control condition eyes closed or eyes open made no difference. This pattern of data makes sense since enhancing vividness through closing one's eyes would only enhance intentions when the envisaged scenario was relevant for the dependent measure.

\subsubsection{Perspective Taken}

One of the advantages of the imagined contact task is that it can be molded to create the best possible conditions for contact to succeed, perhaps in ways that are difficult to achieve in more direct contact scenarios. If imagined contact creates a behavioral script that perceivers can draw upon in making judgments about outgroups, it may be possible to make some subtle modifications to how that script is formed that will have implications for how people see themselves in those encounters. Crisp and Husnu (2010) examined whether directing participants to take a different perspective when imagining an outgroup interaction may have a moderating role on the effectiveness of imagined contact.

Recent research has shown that visual perspective can impact the effects of simulated behavior. Vasquez and Buehler (2007) found that students asked to imagine preparing for an academic test from a third-person perspective reported higher subsequent achievement 
motivation compared to participants who imagined carrying out the task from a first-person perspective. Similarly, Libby, Shaeffer, Eibach and Slemmer (2007) asked respondents to picture themselves voting on the eve of the 2004 US presidential elections. They also instructed participants to use either the first-person or third-person perspective. Participants who pictured themselves voting from the third-person perspective adopted a stronger pro-voting attitude correspondent with the imagined behavior.

Libby and Eibach (2011) argue that taking a third-person perspective helps perceivers frame the imagined event in more abstract terms, and in terms of the broader meaning it has for one's life. In contrast, taking a first-person perspective compels perceivers to frame the imagined events in more contrete terms, focusing on the emotions experienced in that specific context. In other words, whereas taking a first-person perspective might make concrete aspects of the specific situation salient ("a positive encounter with an outgroup member"), taking a third-person perspective makes more abstract goals salient ("I am an egalitarian person"). Because the latter has greater implications for one's sense of self, it should also have a correspondingly greater impact on subsequent behavior.

Crisp and Husnu (2010) allocated sixty undergraduate participants to conditions in which they were asked to imagine a control scene or positive contact with an elderly stranger from either a first-person perspective (i.e. "see the event through your own eyes") or a third-person perspective (i.e. "see the event from an external viewpoint"). Intentions were measured, as was the extent to which participants viewed themselves as having a positive orientation towards positive outgroup contact (e.g., "In general, are you the sort of person who gets on well with elderly people?", 1 = not at all to 7 = very much). As expected, perspective made no difference in the non-relevant control condition. However, imagining intergroup contact from a third-person 
perspective enhanced future contact intentions to a greater extent than imagining the encounter from a first-person perspective, see Table 4. Furthermore, the effects were mediated by an enhanced self-perception of oneself as egalitarian (e.g., "I am the sort of person who gets one well with elderly people", $1=$ not at all to $7=$ very much). This supports the notion that a thirdperson perspective encourages perceivers to view the imagined interaction in relation to their broader goals about the sort of person they are (Libby \& Eibach, 2011).

\subsubsection{Typicality}

A further modification to the imagined contact task was implemented by Stathi et al. (2011). The aim was to enhance the generalization of positive perceptions from the specific outgroup member featured in the imagined interaction to the outgroup as a whole. In the wider literature on intergroup contact theory, the role of the typicality of outgroup members in contact experiences has been shown to exert an important moderating role in generalization. In their account of the Mutual Intergroup Differentiation Model (MIDM), Hewstone and Brown (1986) argued that maintaining group salience can have advantages in the generalization of positive contact effects, and that contact between ingroup and outgroup members should be arranged such that the interacting members are considered typical of their groups, and thus avoid the potential danger of subtyping atypical individuals (Hewstone, 1994; Weber \& Crocker, 1983). Research on the role of salience and outgroup typicality has confirmed the importance of the two factors for generalizing the effects of contact (Brown, Vivian, \& Hewstone, 1999; Wilder, 1984). For instance, Wilder (1984) found that positive contact with typical outgroup members generalizes to the whole outgroup whereas contact with atypical outgroup members does not (see also Wolsko, Park, Judd, \& Bachelor, 2003). 
Building on the idea that group salience and typicality are important for generalization effects, Stathi et al. (2011) compared the effectiveness of imagined contact strategies that emphasized the typical or atypical nature of the imagined outgrouper. The modified instructions were, in the typical condition:

We would like you to take a minute to imagine yourself meeting a British Muslim stranger for the first time. Imagine that this person is a typical British Muslim, he/she dresses in a traditional way, avoids alcohol, reads the Koran and prays five times a day. Imagine that the interaction is relaxed, positive and comfortable. Imagine that you learn about the life and experiences of your conversation partner.

Participants in the atypical condition read:

We would like you to take a minute to imagine yourself meeting a British Muslim stranger for the first time. Imagine that this person is a not a typical British Muslim, he/she dresses in "western" clothes, drinks alcohol, eats pork and does not pray regularly. Imagine that the interaction is relaxed, positive and comfortable. Imagine that you learn about the life and experiences of your conversation partner.

Since contact self-efficacy involves confidence about interacting with the outgroup more generally, it was expected that imagined contact with a typical outgrouper to result in higher contact self-efficacy about future interactions with an atypical outgrouper (i.e., a generalization effect; Ensari \& Miller, 2002). This is precisely what Stathi et al. found: The generalization effect was more likely to occur where the imagined interaction partner was typical versus atypical of the outgroup.

A further experiment showed consonant effects when person- versus group-based imagined contact was compared: The latter enhanced contact self-efficacy. Theoretically, these 
findings support the MIDM which argues that when contact is experienced as being between typical group members it has a greater generalizing effect. In other words, maintaining identity salience (via manipulating the content of the imagined script or the typicality of the conversation partner) affects people's perceived efficacy about future interactions with the outgroup as whole.

An important implication of these findings is that it matters who exactly is imagined in the envisaged scenario. A highly atypical outgroup member will likely be subtyped, as is the case with actual contact, and have little positive impact on the perceiver's attitude towards the outgroup as a whole. In multicultural societies, it may therefore be important how imagined contact is implemented. Berry (1997; Berry \& Annis, 1974) noted that multicultural individuals can construct an identity for themselves in different ways. Take, for example, a Pakistani immigrant to the UK, who has (at least) two potential identities to chose from: 'Pakistani' and 'British'. According to Berry, this individual might chose to assimilate to the most dominant culture (e.g., identify as British only), separate from the dominant culture (e.g., identify as Pakistani only) or integrate (e.g., identity as both British and Pakistani). Imagining contact with an immigrant who is perceived to be entirely assimilated into the host culture may be unlikely to promote attitude change towards the outgroup as a whole because the imagined person may simply be subtyped as an atypical outgrouper (Brown \& Hewstone, 1986). On the other hand, an immigrant who totally separates from the mainstream culture offers no possible basis for similarity based attraction. It is therefore likely that in multicultural contexts, bicultural individuals, who maintain a link to their home culture while simultaneously embracing the host culture, will be most effective as targets in imagined contact interventions. This is because such individuals are both similar enough to the majority group to promote liking, but also typical 
enough of the outgroup to promote generalization of positive attitude change (see Crisp \& Turner, 2011; Benet-Martine, Leu, Lee, \& Morris. 2002).

These findings also counter concerns over maintaining the salience of different identities in contact situations, a process that could be seen to emphasize differences between the groups and reinforce biases. Although not tested in these studies, Stathi et al. (2011) results offer indirect support for the proposed anxiety-reduction and script availability route outlined in Figure 1. Perceivers who feel more self-confident about interactions with the outgroup in general presumably do so because they have formed a cognitive contact script that can apply to members of the outgroup in general, thereby reducing anxiety at the prospect of future interactions.

\subsection{Perceiver-Focused Moderators}

We next consider research that has asked whether perceivers' characteristics or experiences change the effects imagining contact has on intergroup perceptions. We describe three related moderators derived from perceivers' group-relevant experiences: Prior contact, minority status, and ingroup identification.

\subsubsection{Prior Contact}

One reasonable prediction related to imagined contact is that people who have already had prior high levels of contact with the outgroup will be able to more readily generate a positive imagined outgroup interaction (after all, they will have more positive memories of contact to draw upon). Accordingly, Husnu and Crisp (2010a) reasoned that the vividness (and availability) of an imagined contact encounter would be influenced by the extent of participants' prior actual contact experiences, and that the vividness would, in turn, enhance the impact of imagined contact on future contact intentions. Participants were first asked: "How many British Muslims do you know?"; "In everyday life, how often do you encounter British Muslims?”; "In everyday 
life, how frequently do you interact with British Muslims?" and "In everyday life, how much contact do you have with British Muslims?" on a scale from 1 (none) to 7 (a lot). To determine the quality of contact participants were asked to characterize their contact with British Muslims based on the following adjectives: superficial-deep; natural-forced; unpleasant-pleasant; competitive-cooperative; intimate-distant on bipolar scales ranging from 1 to 7.

A composite measure of quality x quantity of prior actual contact was constructed, based upon that commonly used in previous research (e.g., Voci \& Hewstone, 2003). Following this, participants completed either an imagined contact or a control task. Husnu and Crisp (2010b) found that prior contact enhanced post-task intentions to engage in future contact. This finding suggests that while imagined contact is well suited as an intervention in contexts characterized by very low levels of contact (where imagined contact is better than none), the more actual contact participants have had, the greater the impact of imagery on intentions. This may be because imagined outgroup interactions draw, in part, on existing memories of social interaction (including, but not necessarily, other outgroupers). The more readily accessible these memories of prior contact, the more easy it will be for perceivers to form a positive outgroup interaction script.

\subsubsection{Minority/Majority Status}

Stathi and Crisp (2008; Experiment 1) tested whether minorities would be more resistant to the benefits of imagined contact than majorities using a sample of two ethnic groups in Mexico: Mestizos (the ethnic majority group) and Indigenous people (the ethnic minority group). Tropp and Pettigrew's meta-analysis (2006) revealed that the relationship between contact and prejudice is weaker among minority groups than among majority groups (see also Tropp, 2003). This is consistent with the idea that minority group members tend to experience more anxiety at 
the thought of intergroup contact than majority group members (Plant \& Devine, 2003). As such, and consistent with the role of anxiety plays in the model outlined in this chapter, there were good reasons to expect imagined contact to be less effective in changing intergroup perceptions of minority versus majority groups. The results confirmed this hypothesis. Majority group members projected more positive self-traits to the outgroup following positive imagined contact than did minority group members.

\subsubsection{Ingroup Identification}

Why would minorities react less positively to imagined contact with the majority group than vice-versa (i.e., majorities' imagined contact with minorities)? We know that minorities tend to identify with their ingroup more strongly than majorities (Simon \& Brown, 1987) which can be seen as a reaction to the inherent threat associated with minority status (a protective "psychological closing of ranks"). Given that high identification can be associated with more negative outgroup attitudes (Brown et al., 2001; Mummendey, Klink, \& Brown, 2001) aggressive emotional reactions to threat (Crisp, Heuston, Farr \& Turner, 200), or less willingness to embrace prejudice-reduction interventions (Crisp \& Beck, 2005; Crisp, Stone, \& Hall, 2006; Hornsey \& Hogg, 2000), one possible cause of minorities reluctance to project their positive attributes to the outgroup majority is high ingroup identification associated with perceived distinctiveness threat (Ellemers, Spears, \& Doosje, 2002). If high identification is the proximal psychological cause of inhibited projection to outgroups following imagined contact then we would expect to obtain similar results with individuals who identify highly with their ingroup, irrespective of minority versus majority status. Put another way, imagined positive contact should be more effective for individuals who don't identify strongly with their ingroup. 
In a second experiment, Stathi and Crisp (2008) therefore examined the moderating role of ingroup identification (with British students) on imagined contact effects (attitudes towards French students). They found that imagined contact was more successful at promoting projection for participants who did not identify strongly with their national ingroup (see Crisp, Hutter \& Young, 2009, for related findings). This is not to say that imagined contact cannot be successfully applied to highly identifying group members. Rather, that educators and policy makers intending to implement such interventions should recognize that different approaches to promoting positive relations might mean different things to different people (for a discussion of these issues, particularly focused on high ingroup identification and the need to tailor interventions accordingly, see Crisp, Walsh \& Hewstone, 2006; Stone \& Crisp, 2007; Turner \& Crisp, 2010a).

In a final experiment Stathi and Crisp (2008) sought to experimentally manipulate identification. Higher identifiers can be thought of as people for whom the collective self is most salient (at a given point in time) while lower identifiers can be thought of as people for whom the personal self is more salient. Stathi and Crisp proposed that making the personal self-salience (and thus reducing the salience of the collective self) prior to imagined contact, would reduce contextually salient ingroup identification. This can be achieved by varying the order of ratings of the self and the outgroup (Cadinu \& Rothbart, 1996). When asked to describe the self first, people think of their personal, idiosyncratic characteristics (personal self) before being asked to think of an outgroup. Under such conditions the a priori positive image of the self (Sears, 1983) is potentially more easily generalized to the outgroup. In contrast, when people think of the characteristics of the outgroup first, the social self is made salient. Since the outgroup is by definition (more) distant from the social self, but not necessarily from the personal self, people 
might project less positivity to the outgroup. Taking into consideration that social projection involves the activation of the personal self (Clement \& Krueger, 2000) and that outgroup priming leads to the activation of the social self (Hall \& Crisp, 2008) following imagined contact, and when the self (versus the outgroup) is salient, projection of positivity should be greatest. Consistent with this theorizing, imagined contact promoted more positive outgroup perceptions when the personal, versus collective, self was salient. Relating this finding back to Experiment 1, a similar pre-contact task may also enhance the effectiveness of imagined contact for minority group members, who are also sometimes found to perceive contact with different groups as identity threatening (Stephan, Diaz-Loving, \& Duran, 2000). In sum, if the personal self is activated prior to the application of the intervention, identity threat associated with the thought of intergroup interaction may be mitigated and the bias-reducing effects of imagined contact can be realized.

In summary, the research described above provides not only specification of important boundary and facilitating conditions to assist in the practical implementation of imagined contact, but also support for the underlying mechanisms outlined in Figure 1. Modifications to the basic imagined contact task instructions have yielded enhancements to outcomes consistent with the proposed script availability mechanism (e.g., elaboration, perceptual focus) and anxietyreduction mechanism (typicality, minority status). While typically studies have focused on seeking support for either the cognitive or affective underlying mechanisms (but see Husnu \& Crisp, 2010a; Experiment 2), we would consider the respective cognitive and affective processes identified in the studies reviewed above as separate, but intimately linked, components of a single fundamental process driving imagined contact effects. We can draw an analogy with interventions focused around 'perspective-taking', which also yield pro-social outcomes (e.g., 
intergroup helping behavior). Perspective-taking increases helping behavior through the cognitive process of imagining oneself in the shoes of another (including outgroup members; Galinksy \& Moskowitz, 2000); while this triggers a consonant affective process - increased empathy (Batson et al., 1997). These cognitive and affective dimensions of perspective taking have also been found to be part of the process through which direct contact reduces prejudice (Aberson \& Haag, 2007; Harwood, Hewstone, Paolini, \& Voci, 2005; Pettigrew \& Tropp, 2008; Tam et al., 2006; Swart, Hewstone, Christ, \& Voci, 2011). We would therefore argue that imagined contact works primarily by providing the cognitive basis for more positive expectations about outgroup contact, which correspondingly reduces anxiety and promotes more positive affective reactions; cognitive and affective reactions that can perhaps be considered two sides of the same (processing) coin.

\subsubsection{Other Moderators}

The research reviewed above suggests that the basic form of imagined contact will be less effective when ingroup identification is high, and prior contact is low. One may therefore ask whether there are other individual differences in experience, attitude or ideological orientation that could moderate the effects of imagined contact. One such source of individual variation is intergroup anxiety. We have shown that imagined contact reduces intergroup anxiety, and this is an important process leading to greater tolerance (Crisp \& Turner, 2009; Turner et al., 2007). However, high levels of anxiety can also compel people to avoid intergroup contact altogether (Plant \& Devine, 2003) and for such individuals even considering the possibility of a positive outgroup interaction may simply be impossible, rending imagined contact ineffective.

Birtel and Crisp (2011) recently tested whether pre-contact intergroup anxiety does make imagining contact more cognitively effortful, and if it does, whether this detracts from its 
effectiveness. The outcome measure was the independently coded quality of a video communication directed to the outgroup (international students at the University of Kent). The authors found that whereas participants higher in intergroup anxiety did indeed find imagining a positive outgroup interaction more difficult than participants lower in intergroup anixety (as measured by the Stroop test; Stroop, 1935), this did not detract from the effectiveness of the approach for improving intergroup behavior. Specifically, whereas higher levels of anxiety led to more disfluent video messages, imagining contact eliminated this negative impact of anxiety, bringing the quality of the message up to similar levels as for low anxiety participants. This is consistent with the notion that imagined contact provides a cognitive script that individuals can draw upon to improve the fluency of subsequent interactions.

This work suggests that even for people holding pre-existing negative attitudes towards the outgroup, imagined contact will be effective; with the caveat that it will be more cognitively challenging for such perceivers. Future research should examine whether imagined contact is similarly effective for people higher in implicit or explicit prejudice, or other ideological orientations associated with prejudice such as Right Wing Authoritarianism (Altemeyer, 1981) or Social Dominance Orientation (Sidanius \& Pratto, 2001). In such contexts, if the effectiveness of imagined contact is constrained, variants of the basic task may be needed to strengthen its effectiveness. The variants reviewed in the section on task-focused moderators (e.g., elaboration, visual perspective) may provide some ways in which this can be achieved.

\section{Practical and Paradigmatic Implementations}

Imagined contact represents a highly flexible implementation of contact theory - no actual or extended contact is required, it is cheap, easy to use, and effective. In this section we discuss 
the potential for its application as an intervention, particularly in educational settings, and in the context of the broader canvass of existing anti-discriminatory programs.

The majority of programs used to change intergroup attitudes in educational settings can be divided into two types: The multicultural curricula approach (Appl, 1996) and the anti-racist approach (Dei, 1996). Multicultural curricula programs involve teaching children about the culture and lifestyle of minority groups (e.g., Sleeter \& Grant, 1994). The idea is that if prejudice is caused by ignorance, then teaching children about the outgroup is the solution (Appl, 1996). However, this perspective is based on the assumption that children are passive recipients of information. In fact evidence suggests that children, like adults, actively construct schemas, based on their own observations, which they then use to understand and interpret their social world (Piaget, 1970). Accordingly, multicultural curricula programs have not consistently achieved desired reductions in prejudice (e.g., Koeller, 1977; Lessing \& Clarke, 1976).

Existing interventions, such as the multicultural curricula approach, are typically developed from intuition and creative insight (Aboud \& Levy, 2000), rather than research-led theory, and this could be part of what contributes to their uncertain effectiveness. In contrast, interventions developed from contact theory are based on methods that have been tried and tested in controlled laboratory settings. Unlike traditional interventions, contact-based strategies generate positive, affective, emotional responses to the outgroup, which seems critical in generating robust and lasting attitude change (Pettigrew, 1998). They also involve active thought rather than the passive receipt of information, which is advocated by educational psychologists over more passive approaches (Randi \& Corno, 2000). But there are two difficulties in applying contact-based interventions. First, bringing together members of different groups is likely to be costly and time consuming. Second, as we have noted throughout this chapter, such direct or 
even extended contact interventions can only be applied in contexts where group members have the opportunity (or indeed the inclination) for contact in the first place.

We have argued that imagined contact may offer the means of effectively implementing contact theory in educational settings (see Crisp et al., 2008). It involves only a short, simple task, and can be implemented with little obvious expense. It also has the potential to be integrated with the traditional interventions outlined above. While traditional approaches involve discussing cultural characteristics of outgroup members, or discussing the problems of racist attitudes and behavior; they are essentially passive approaches. In contrast, when people imagine an intergroup interaction they are likely to actively engage in conscious processes that parallel the processes involved in actual intergroup contact. They may, for example, think about what they would learn about the outgroup member, how they would feel during the interaction, and how this would influence their perceptions of the outgroup more generally.

We do not argue that traditional approaches should be abandoned. Rather, they might be effectively incorporated with imagined contact. Thus, rather than listen to a teacher extol the benefits of multiculturalism and tolerance, students could be asked to imagine having an interaction with an outgroup member in which they learn new and interesting things about the other culture (a more active way of learning about multiculturalism), or where they learn what it might be like to be the victim of discrimination (a more active anti-racism approach). Participants could then discuss as a group what they learned from the imagination task in order to reinforce its impact. This type of exercise would introduce the same topics as the traditional approaches but in a more active and interactive way. 


\subsection{Evidence from School Interventions}

There are two recent studies that are notable in their attempt to tested the effectiveness of imagined contact as an educational intervention. Cameron et al. (in press) conducted a test of the imagined contact intervention with young children. Non-disabled children, aged between 5 and 10 years, were asked to spend three minutes using pictures and photographs to create a story that featured the participant themselves and a disabled child playing together in a park. They were subsequently asked to describe the things they imagined doing that were 'fun and interesting'. Children assigned to a control condition did not complete this activity. Attitude towards the nondisabled and disabled people and intended future behavior towards disabled people were then assessed through a structured interview. In addition, two perceived stereotypes associated with disabled people, derived from the stereotype content model, were examined: warmth and competence (Fiske, Cuddy, Glick, \& Xu, 2002). The intervention was effective: Participants who had imagined intergroup contact showed less bias in their general attitudes towards disabled people, and greater warmth and competence ratings regarding disabled people. Moreover, they were also more likely to want to be friends with disabled children following imagined contact, see Figure 8.

In another study, Vezzali, Capozza, Giovannini, and Stathi (in press) tested Italian $5^{\text {th }}$ graders (average age 10 years 5 months), who were randomly assigned to an imagined contact or a control condition. Participants in the experimental condition took part in three intervention sessions in groups of five or six children, with each session lasting about 30 minutes. Specifically, they were asked to imagine having a pleasant interaction with an unknown immigrant child who had just arrived in the country. To avoid subtyping of the outgroup member and to ensure the positive effects of the intervention generalize to the entire outgroup, in each 
session, participants imagined contact with a different child, in a different context (school, neighborhood, park; see also Husnu \& Crisp, 2010b for this method of establishing imagined 'contextual variability'). They were then given fifteen minutes to write down a detailed description of the interaction, before having a ten minute discussion with the research assistant regarding what they had imagined. In order to examine the longevity of the imagined contact effect, the dependent measures were assessed one week later. Implicit attitude (measured using the Child IAT; Baron \& Banaji, 2006), likelihood of self-disclosure, and behavioral intentions (whether they would be happy to meet, play with, or have an ice-cream with an outgroup member) towards immigrant children were assessed. The results revealed that children who had imagined contact over the preceding three sessions were subsequently more willing to selfdisclose to the outgroup, had more positive behavioral intentions, and showed reduced implicit intergroup bias on the Child IAT.

The findings of Cameron et al. (in press) and Vezzali et al. (in press) are important because they show that imagined contact can be successfully applied in an education settings, and can have benefits for even quite young children. Moreover, the effect of imagined contact was shown to last for up to a week, going some way to alleviating concerns that the effect would be transient. However, they also highlight the importance of adapting the task to the age of the child. Although the imagination tasks used in these studies were not directly compared to the relatively brief instructions typically given to adults in the laboratory, these findings suggest that when applying the intervention in schools a more involved and sustained task may be necessary.

\subsection{Secondary Transfer Effects}

Imagined contact is also providing a new paradigm with which to explore current issues in contact theory. Pettigrew (2009) found that direct contact with a single outgroup member can 
result in more positive attitudes not only towards that individual's group, but also towards other groups, a phenomenon described as secondary transfer effects. Harwood et al. (in press) examined whether even simply imagining contact could enable secondary transfer effects. Participants were asked to imagine one of three things: A positive interaction with an unfamiliar illegal immigrant, a negative interaction with an unfamiliar illegal immigrant, or in a control condition, an outdoor scene. Participants then rated their feelings about illegal immigrants and 21 other groups, who had been rated by three independent coders for how similar they were to illegal immigrants. As expected, participants had a more positive attitude towards illegal immigrants in the positive contact condition than in the negative contact condition, with the control condition falling between the two. Of particular interest was the effect of imagined contact on attitudes towards other groups. The effect of positive imagined contact with illegal immigrants on attitudes towards illegal immigrants subsequently generalized to attitudes about Mexican-Americans, legal immigrants, Asian-Americans, homeless people, political refugees, Black people, democrats, and professors. Moreover, there was a stimulus generalization gradient whereby strongest effects emerged for the groups who were perceived as most similar to illegal immigrants (e.g., Mexican-Americans, Asian Americans, homeless people, and political refugees), with weaker or null effects for groups perceived as most different (e.g., graduate students, social science majors). Harwood and colleagues noted that this shows that attitudes may be organized in some sort of semantic network, and that changes to one attitude will generalize to others that are nearby in the network, but less so to those which are, semantically, further away.

These findings should show that imagined contact is not a narrow and limited intervention, but can have a broad impact on intergroup relations. The findings also suggest that imagined 
contact could be used to change attitudes for people who are resistant to imagining positive intergroup contact to a particular group, perhaps because of socio-historical reasons. In these situations, Harwood and colleagues (in press) argue that a proxy group, which is perceived as similar to the target outgroup, but is not perceived in quite such a negative light, could be used instead for the imagined contact task. This may in turn, result in secondary transfer to the more threatening target outgroup.

\section{Theoretical Implications and Suggestions for Future Research}

In this chapter we have described the theoretical basis, empirical support, and practical applications of a new intervention strategy for improving intergroup attitudes: Imagined intergroup contact. The approach has been found to improve intergroup attitudes at both the explicit (Turner et al., 2007a) and implicit level (Turner \& Crisp, 2010b), it promotes positive trait projection (Stathi \& Crisp, 2008), encourages intentions to engage in actual contact (Husnu $\&$ Crisp, 2010a). It works through affective processes, reducing anixety (Turner et al., 2007a, Husnu \& Crisp, 2010a) and promoting outgroup trust (Turner et al., in press; Vezzali et al., in press-b) as well as through cognitive processes, enhancing the availability of positive scripts, measured via likelihood estimates (Husnu \& Crisp, 2011), reported vividness, subjective reports of ease of retrieval (Husnu \& Crisp, 2010a), and meta-cognition (Crisp \& Husnu, 2011). It is more effective when the imagined interaction is accompanied by elaboration instructions (Husnu \& Crisp, 2010a; b; 2011), when the imagined interaction features typical outgroupers (Stathi, Crisp \& Hogg, 2011), and for majorities compared to minorities, for lower identifiers, and when the self is salient (Stathi \& Crisp, 2008). Imagined contact reduces prejudice against a range of different target groups (Harwood et al., 2010) including on the basis of age (Turner et al., 2007a), nationality (Stathi \& Crisp, 2008), sexuality (Turner et al., 2007a), ethnicity (Husnu \& Crisp, 2010a; Stathi \& Crisp, 2008), mental health (West et al., 2010), religion (Husnu \& Crisp, 
2010b; Turner \& Crisp, 2010b), immigration status (Turner et al., in press; Vezzali et al., in press-a), weight (Turner \& West, in press) and even those who are highly negatively stereotyped (West et al., 2010) or dehumanized (Brambilla, Ravenna, \& Hewstone, in press; Vezzali et al., in press- $b$ ). Below we discuss the theoretical implications and routes for future research emerging from this review.

\subsection{Do Real Conflicts Require Real Solutions?}

Lee and Jussim's (2010) thoughtful commentary notes of imagined contact, "The method is relatively simple, easy, and inexpensive to use. Consequently, it has a great deal of flexibility, and can be fairly easily implemented almost anywhere. Furthermore, an impressive body of research shows that it often has the intended effect of reducing prejudice" (p.130). However, they also critique mainstream social psychology's tendency to focus on individual cognitive processes at the expense of a macro-level analysis that takes into account the real social, political, cultural and economic context in which the groups reside (of which they say our approach is a prime example). They argue, in essence, that laboratory studies of underlying cognitive processes are ill equipped to solve the problem of prejudice. We agree with the need to take a wide perspective in tackling social issues, but would counter that we cannot solve such problems without experimental social psychology (the pioneering work of Allport, Tajfel and many others taught us this). We can only understand, and attenuate, prejudice by understanding both the individual, the group and the society; not only the socio- political (and economic, cultural, and historical dimensions), but also the psychological (see Crisp \& Turner, 2010).

In its ability to reduce anxiety and promote a more positive orientation towards outgroups, imagined contact may, in fact, be ideally suited to tackling even violent, antagonistic conflicts. Indeed it is notable that positive effects of imagined contact have been demonstrated in contexts 
of intractable conflict (e.g., the Cyprus conflict; Husnu \& Crisp, 2010b) and even against highly dehumanized groups (Brambilla et al, in press; Vezzali et al., in press). Disagreements aside, Lee and Jussim highlight an important point that we too endorse: Whether prejudice is subtle or blatant, like all psychological interventions, imagined contact should be seen as part of a larger solution that is comprised of multiple interventions, developed from multiple perspectives. A comprehensive solution to the problem of prejudice will involve a multi-focused interventions that tackle the complex and multi-layered motivational, ideological, economic and social contributors to this most pervasive of social problems. But just as a purely cognitive focus is not enough, nor should we ignore the power and potential of social cognitive approaches in helping us tackle these problems.

\subsection{Imagined, Extended and Direct Contact}

Contact theorists have distinguished between direct and indirect forms of contact (e.g., Brown \& Hewstone, 2005; Crisp \& Turner, 2009; in press; Paolini et al., 2004; Turner et al., 2007b). Direct intergroup contact typically refers to face-to-face encounters between members of two different groups, for example cross-group friendship. In contrast, indirect intergroup contact typically refers to interventions which are based on the theoretical principles of intergroup contact, but do not actually involve any face-to-face interaction between members of two groups.

In many ways extended and imagined contact - both forms of indirect contact - are similar. Imagined and extended contact do not involve face-to-face encounters, so are less likely to provoke intergroup anxiety (Plant \& Devine, 2006; Stephan \& Stephan, 1985). Extended, but especially imagined, contact should also be easy to apply practically as prejudice-reduction interventions, in contexts where interactions between the relevant groups are difficult, rare or non-existent. On the other hand, direct experiences produce stronger attitudes on an issue than 
indirect experiences like imagined or extended contact (Fazio, Powell, \& Herr, 1983; Fazio \& Zanna, 1978; Stangor, Sullivan, \& Ford, 1991). In other ways imagined contact is more similar to direct contact than to extended contact. Both actual and imagined contact involve the perceivers themselves interacting with an outgroup member, possibly producing stronger, more accessible and more persistent attitudes than extended contact because it is based on a personal (albeit imagined) contact experience (Fazio et al., 1983).

The differences between direct, extended, and imagined contact are many, varied, and complex. Nonetheless, the respective advantages and disadvantages of each type of contact illustrate their complementary nature. In socially integrated contexts, for example, direct contact may be the most effective strategy. Where people highly identify with the ingroup, extended contact might work best because of its' ability to change ingroup behavioral norms. In segregated settings where there is relatively low opportunity for contact, where people have only had no or negative past contact with the outgroup, imagined contact may be most useful.

\subsection{A Continuum of Contact Strategies}

Rather than pitting different contact strategies against one another, a more productive approach may be to explore the possibilities of constructing integrated strategies, in line with Allport's (1954b) original assertions, along a 'continuum' of contact strategies (Crisp \& Turner, 2009; see also Harwood, 2010). In this chapter we have argued that imagined contact might be usefully applied is as the first stage in a programmatic intervention that also involves the introduction of extended and direct contact interventions at a later stage. For instance, for groups at early stages of co-existence there may be high segregation and little opportunity, or inclination, for contact. At this point in relations imagined contact may be the only viable intervention to help encourage attitude change and intentions to engage in preliminary contact 
(or at least to ensure that when that contact does occur, it does so with open minds and a reasonable chance of success). At intermediate stages when boundaries have begun to permeate, and some positive interactions initiated, extended contact will work well to reinforce the impact of isolated (but known) contact encounters. Increasing extended contact may then lead to a cascade of positive interactions, along with all the benefits associated with actual intergroup contact. The research reviewed in this chapter provides empirical support for this idea, and reinforces the view that imagined contact may prove highly useful as a 'first step strategy', laying the groundwork for subsequent and more tangible, extended and actual contact strategies.

\subsection{Allport's Legacy Revisited}

We began this chapter discussing the seminal work of Gordon Allport in his book The Nature of Prejudice (1954b). This review of research on imagined contact underscores Allport's impressive ability to predict the future of intergroup contact theory. In this chapter, we have shown that imagined contact provides a road map to more positive intergroup relations, a route which takes us from prejudice, intolerance, and segregation through to positive, comfortable and successful intergroup contact. It does so by encouraging a range of increasingly approach oriented outcomes, from more positive intergroup attitudes, to a greater desire to approach the outgroup and a feeling of self-efficacy in one's ability to achieve this, through to more positive non-verbal behavior when anticipating an intergroup encounter. Moreover, it achieves these goals by reducing the barriers to approaching the outgroup (e.g., anxiety, avoidance) and giving people the tools (e.g., behavioral scripts) and positive emotional responses (e.g., trust) that make them feel able to engage in contact. What we have showed in this chapter resonates very closely with what Allport predicted: Essentially, that there would be a continuum of contact, whereby an intervention at the "milder...fantasy level" might be an "effective first step" that "intercultural 
programs should start with" before they "move gradually into more realistic methods of training" (1954b, p. 543).

It seems that we have come full circle since Allport (1954b) initially made his contact hypothesis. Over the past half century, contact researchers have invested heavily in identifying the optimal conditions under which contact with individual outgroup members is effective at generating more positive attitudes towards the entire outgroup (for a review see Brown \& Hewstone, 2005). A wide range of conditions were suggested. However, more recently theorists, alongside the findings from Pettigrew and Tropp's (2006) meta-analysis, suggest that such conditions are in fact facilitating rather than essential. Does this mean that Allport was wrong in his identification of these (facilitating) conditions? We argue not, and that just because contact can work in the absence of such conditions, it is more likely to work when the conditions are optimal. Allport claimed that "wholly superficial contact" where "contacts are casual, or else firmly frozen into superordinate-subordinate relationships....does not dispel prejudice; it seems more likely to increase it" (p. 251). He argued that this would be the case in part because "we are sensitized to perceive signs that will confirm our stereotypes" (p. 252).

Such realities underscore the need for approaches like imagined contact; and the need to mentally prepare people for the challenges of intergroup contact in vivo. We should not only be hesitant to discard the facilitating conditions (e.g., equal social status, co-operation and common goals) gleaned from 60 years on contact research; but also recognize that it is not only these external conditions that give contact a fighting chance of success. The internal state of the perceiver is also critical, and imagined contact, in it's ability to create a mindset focused on the potential positives of intergroup contact, may be an important technique for mentally preparing people to engage in more positive intergroup relations. By encouraging people to develop an 
interest in engaging with outgroups, imagined contact may be an invaluable tool in ensuring that contact, when it arises, is not superficial, ineffective, or antagonistic, but rather enjoyable, appelaing and inherently enriching.

We also believe that imagined contact breaths new life in to another of Allport's key assertions - the role of cognition in reducing prejudice. Pettigrew and Tropp's (2006) metaanalysis demonstrated that the most powerful processes underlying contact effects were affective, with intergroup anxiety emerging as particularly important. Although it works through affective processes, imagined contact is by definition, primarily a cognitive intervention - it relies on our ability to mentally articulate a possible future scenario. Research on imagined contact demonstrates the importance of continued exploration, and exploitation, of cognitive processes relevant to reducing prejudice. These benefits can be seen in a wide range of domains, beyond even the contact sphere. For instance, imagined contact has informed research on the prejudice-reducting potential of eliciting nostalgic intergroup memories (Turner, Wildshut, \& Sedikides, in press) as well as providing a new approach to reducing stereotype threat (Abrams et al., 2008; Crisp \& Abrams, 2008). More generally, research on imagined contact can be seen as part of a wider development of cognitive interventions for reduce prejudice such as perspective-taking (Hodson, Choma, \& Costello, 2009) or the priming of incremental theories (Halperin et al., 2011). These and other new forms of cognitive intervention, focusing not just on mental representation of intergroup differences and similarities (see Crisp \& Hewstone, 2007), but the mental articulation of contact-related thought processes, may offer new insights into the role that cognitive processes can play in promoting more positive intergroup relations. 


\section{Conclusions}

At the start of this chapter we noted a highly cited declaration from the 1947 constitution of UNESCO - the United Nations Educational, Scientific and Cultural Organization, "since wars begin in the minds of men, it is in the minds of men that the defenses of peace must be constructed". The research reviewed in this chapter is the embodiment of this sentiment. Over the last 60 years psychologists have sought to understand the nature of prejudice and on this basis develop interventions to promote more positive intergroup relations. New and emerging conflicts serve as vivid reminders of the importance of this endeavor; immigration and globalization underscore the need for informed policies that encourage co-operation and tolerance. Our ability to envisage the world different from that which we know is a defining characteristic of human cognition. Imagined contact capitalizes on this capacity, and provides a new, simple, yet effective means of promoting tolerance and more positive intergroup perceptions. We believe it offers significant potential for policy makers and educators in their efforts to improve social harmony, while standing as the strongest possible testament to the power, flexibility and enduring appeal of Gordon Allport's intergroup contact hypothesis. 


\section{References}

Aberson, C., \& Haag, S. C. (2007). Contact, perspective taking, and anxiety as predictors of stereotype endorsement, explicit attitudes, and implicit attitudes. Group Processes and Intergroup Relations, 10, 179-201.

Aboud, F.E. \& Levy, S.R. (2000). Interventions to reduce prejudice and discrimination in children and adolescents. In Stuart Oskamp, (Ed.), Reducing prejudice and discrimination (pp. 269-293). NJ, US: Lawrence Erlbaum Associates Publishers.

Abrams, D., Crisp, R. J., Marques, S., Fagg, E., Bedford, L., \& Provias, D. (2009). Threat inoculation: Experienced and imagined intergenerational contact prevents stereotype threat effects on older people's math p erformance. Psychology and Aging, 23, 934-939.

Allport, G. W. (1954a). The historical background of modern social psychology. In G. Lindzey (ed.), Handbook of Social Psychology (Vol. 1, pp. 3-56). Reading, MA: Addison-Wesley.

Allport, G. W. (1954b). The Nature of Prejudice. Cambridge, MA: Perseus Books.

Altemeyer, B. (1981). Right-wing authoritarianism. University of Manitoba Press.

Anderson, C. A. (1983). Imagination and expectation: the effect of imagining behavioral scripts on personal intentions. Journal of Personality and Social Psychology, 45, 293-305.

Anderson, C. A., \& Godfrey, S. S. (1987). Thoughts about actions: The effects of specificity and availability of imagined behavioural scripts on expectations about oneself and others. Social Cognition, 5, 238-258.

Angermeyer, M. C. \& Matschinger, H. (2005). Causal beliefs and attitudes to people with schizophrenia: Trend analysis based on data from two population surveys in Germany. British Journal of Psychiatry, 186, 331-334. 
Appl, D. J. (1996). Recognising diversity in the early childhood classroom: Getting started. Teaching Exceptional Children, 28, 22-25.

Baron, A. S., \& Banaji, M. R. (2006). The development of implicit attitudes: Evidence of race evaluations from ages 6 and 10 and adulthood. Psychological Science, 17, 53-58.

Brambilla, M., Ravenna, M., \& Hewstone, M. (in press). Changing stereotype content through mental imagery: Imagining intergroup contact promotes stereotype change. Group Processes and Intergroup Relations.

Bandura, A. (1986). Social foundations of thought and action: A social cognitive theory. Englewood Cliffs, NJ: Prentice- Hall, Inc.

Bandura, A. (2001). Social cognitive theory: An agentic perspective. Annual Review of Psychology, 52, 1-26.

Bandura, A., \& Schunk, D. H. (1981). Cultivating competence, self-efficacy and intrinsic interest through proximal self- motivation. Journal of Personality and Social Psychology, 41, 586598.

Batson, C. D., Polycarpou, M. P., Harmon-Jones, E., Imhoff, H. J., Mitchener, E. C., Bednar, L. L., Klein, T. R., \& Highberger, L. (1997). Empathy and Attitudes: Can Feeling for a Member of a Stigmatized Group Improve Feelings Toward the Group? Journal of Personality and Social Psychology, 72, 105-118.

Benet-Martínez, V., Leu, J., Lee, F., \& Morris, M. (2002). Negotiating biculturalism: Cultural frame-switching in biculturals with 'oppositional' vs. 'compatible' cultural identities. Journal of Cross-Cultural Psychology, 33, 492-516.

Berry, J. W. (1997). Immigration, acculturation, and adaptation. Applied Psychology: An International Review, 46, 5-34. 
Berry, J. W. \& Annis, R. C. (1974). Acculturation stress: The role of ecology, culture and differentiation. Journal of Cross-cultural Psychology, 5, 382-406.

Bigler, R. S., \& Hughes, J. M. (2010). Reasons for skepticism about the efficacy of simulated contact interventions. American Psychologist, 65, 131-132.

Birtel, M. D., \& Crisp, R. J. (2011). Imagining intergroup contact is more cognitively difficult for people higher in intergroup anxiety, but this does not detract from its effectiveness. Manuscript submitted for publication.

Blackstock, M. D. (2001). Where is the trust? Using trust-based mediation for first nations dispute resolution. Conflict Resolution Quarterly, 19, 9-30.

Brown, R., \& Hewstone, H. (2005). An integrative theory of intergroup contact. In M. P. Zanna (Ed.), Advances in Experimental Social Psychology (Vol. 37, pp. 255-343). San Diego, CA: Academic Press.

Brown, R., Vivian, J., \& Hewstone (1999). Changing attitudes through intergroup contact: The effects of group membership salience. European Journal of Social Psychology, 29, 741764.

Brown, R., Maras, P., Masser, B., Vivian, J., \& Hewstone, M. (2001). Life on the ocean waves: Testing some intergroup hypotheses in a naturalistic setting. Group Processes and Intergroup Relations, 42, 81-87.

Cadinu, M. R., \& Rothbart, M. (1996). Self-anchoring and differentiation processes in the minimal group setting. Journal of Personality and Social Psychology, 70, 661-677.

Cameron, L., Rutland, A., Turner, R. N., Blake, B., Holman-Nicolas, R., \& Powell, C. (in press). Changing attitudes with a little imagination: Imagined contact effects on young children's implicit attitudes. Anale de Psicologia. 
Carroll, J. S. (1978). The effort of imagining an effect on expectations for the event: An interpretation in terms of the availability heuristic. Journal of Experimental Social Psychology, 14, 88-96.

Clement, R. W., \& Krueger, J. (2002). Social categorization moderates social projection. Journal of Experimental Social Psychology, 38, 219-231.

Crisp, R. J., \& Abrams, D. (2008). Improving intergroup attitudes and reducing stereotype threat: An integrated contact model. In W. Stroebe, \& M. Hewstone (Eds.). European Review of Social Psychology (vol. 19, pp. 242-284). Hove, E. Sussex: Psychology Press (Taylor \& Francis).

Crisp, R. J., \& Beck, S. R. (2005). Reducing intergroup bias: The moderating role of ingroup identification. Group Processes and Intergroup Relations, 8, 173-186.

Crisp, R. J., Birtel, M. D., \& Meleady, R. (2011). Mental simulations of social thought and action: Trivial tasks or tools for transforming social policy? Current Directions in Psychological Science, 20, $261-264$.

Crisp, R. J., \& Hewstone, M. (2007). Multiple social categorization. In M. P. Zanna (Ed.). Advances in Experimental Social Psychology (vol. 39, pp. 163-254). Orlando, FL: Academic Press.

Crisp, R. J. \& Husnu, S. (2011). Attributional processes underlying imagined contact effects. Group Processes and Intergroup Relations, 14, 275-287.

Crisp, R.J., Husnu, S., Meleady, R., Stathi, S., \& Turner, R. N. (2010). From imagery to intention: A dual route model of imagined contact effects. In W. Stroebe, \& M. Hewstone (Eds.). European Review of Social Psychology (vol. 21, pp: 188-236). Hove, E. Sussex: Psychology Press (Taylor \& Francis). 
Crisp, R. J., Stathi, S., Turner, R. N., \& Husnu, S. (2008). Imagined intergroup contact: Theory, paradigm, and practice. Personality and Social Psychology Compass, 2, 1-18.

Crisp, R. J., Stone, C. H., \& Hall, N. R. (2006). Recategorization and subgroup identification: Predicting and preventing threats from common ingroups. Personality and Social Psychology Bulletin, 32, 230-243.

Crisp, R. J., Walsh, J., \& Hewstone, M. (2006). Crossed categorization in common ingroup contexts. Personality and Social Psychology Bulletin, 32, 1204-1218.

Crisp, R. J., \& Turner, R. N. (2009). Can imagined interactions produce positive perceptions? Reducing prejudice through simulated social contact. American Psychologist, 64, 231-240.

Crisp, R. J., \& Turner, R. N. (2010). Have confidence in contact. American Psychologist, 65, 133-134.

Crisp, R. J. \& Turner, R. N. (2011). Cognitive adaptation to the experience of social and cultural diversity. Psychological Bulletin, 137, 242-266.

Crisp, R. J., \& Turner, R. N. (in press). Imagined intergroup contact: Refinements, debates and clarifications. Chapter to appear in G. Hodson \& M. Hewstone (Eds.), Advances in Intergroup Contact. Psychology Press (Taylor \& Francis).

Crisp, R. J., Walsh, J., \& Hewstone, M. (2006). Crossed categorization in common ingroup contexts. Personality and Social Psychology Bulletin, 32, 1204-1218.

Dei, G. J. S. (1996) Anti-racism education: Theory and Practice. Halifax, Canada: Fernwood.

Dovidio, J. F., Gaertner, S. L., Kawakami, K., \& Hodson, G. (2002). Why can't we just get along? Interpersonal biases and interracial distrust. Cultural Diversity and Ethnic Minority Psychology, 8, 88-102. 
Dovidio, J., Glick, P., \& Rudman, L. A. (2005). Introduction: Reflecting on The Nature of Prejudice: Fifty Years after Allport. I. J. F. Dovidio, P. Glick, L. A. Rudman (Eds), On the nature of prejudice: Fifty years after Allport. (pp. 1-15). Malden: Blackwell Publishing.

Dovidio, J. F., Hebl, M., Richeson, J. A., \& Shelton, J. N. (2006). Nonverbal communication, race, and intergroup interaction. In V. Manusov, \& M. L. Patterson (Eds), The Sage handbook of nonverbal communication. (pp. 481-500). Thousand Oaks, CA: Sage Publications

Ellemers, N., Spears, R., \& Doosje, B. (2002). Self and social identity. Annual Review of Psychology, 53, 161-186.

Eller, A., \& Abrams, D. (2004). Come together: Longitudinal comparisons of Pettigrew's reformulated intergroup contact model and the common ingroup identity model in AngloFrench and Mexican-American contexts. European Journal of Social Psychology, 34, 229256.

Ensari, N., \& Miller, N. (2002). The out-group must not be so bad after all: the effect of disclosure, typicality and salience on intergroup bias. Journal of Personality and Social Psychology, 83, 313-329.

Escales, J. E., \& Luce, M. F. (2004). Understanding the effects of process-focused versus outcome-focused thought in response to advertising. Journal of Consumer Research, 31, 274-285.

Fan, C., \& Mak, A. (1998). Measuring social self- efficacy in a culturally diverse student population. Social Behavior and Personality, 26, 131-144.

Fazio, R. H. \& Zanna, M. P. (1978). On the predictive validity of attitudes: The roles of direct experience and confidence. Journal of Personality, 46, 228-243. 
Fazio, R. H., Powell, M. C., \& Herr, P. M. (1983). Toward a process model of the attitudebehavior relation: Accessing one's attitude upon mere observation of the attitude object. Journal of Personality and Social Psychology, 44, 723-735

Feddes, A. R., Noack, P., \& Rutland, A. (2009). Direct and extended friendship effects on minority and majority children's interethnic attitudes: A longitudinal study. Child Development, 80, 377-390.

Feltz, D. L., \& Riessinger, C. A. (1990). Effects of in vivo emotive imagery and performance feedback on self-efficacy and muscular endurance. Journal of Sport and Exercise Psychology, 12, $132-143$.

Feltz, D. L., \& Landers, D. M. (1983). The effects of mental practice on motor skill learning and performance: A meta-analysis. Journal of Sports Psychology, 5, 25-57.

Fiske, S. T., Cuddy, A. J. C., Glick, P. \& Xu, J. (2002). A model of (often mixed) stereotype content: Competence and warmth respectively follow from perceived status and competition. Journal of Personality and Social Psychology, 82, 878 - 902.

Galinksy, A. D., \& Moskowitz, G. B. (2000). Perspective-taking: Decreasing stereotype expression, stereotype accessibility, and in-group favoritism. Journal of Personality and Social Psychology, 78, 708-724.

Galton, F. (1883). Inquiries into human faculty and its development. London: Macmillan.

Goldman, A.L. (2005). Simulationist models of face-based emotion recognition. Cognition, 94 , 193-213.

Gollwitzer, P. M. (1993). Goal achievement: The role of intentions. In W. Stroebe \& M. Hewstone (Eds.), European Review of Social Psychology (Vol. 4, pp. 141-185). Chicester: Wiley. 
Greenwald, A. G., McGee, D. E., \& Schwartz, J. L. K. (1998). Measuring individual differences in implicit cognition: The implicit association test. Journal of Personality and Social Psychology, 74, 1464-1480.

Gregory, W. L., Cialdini, R. B., \& Carpenter, K. M. (1982). Self-relevant scenarios as mediators of likelihood estimates and compliance: Does imagining make it so? Journal of Personality and Social Psychology, 43, 89-99.

Gudykunst, W. B., \& Nishida, T. (1986). The influence of cultural variability on perceptions of communication behavior associated with relationship terms. Human Communication Research, 13, 147-166.

Halperin, E., Russell, G. A., Trzesniewski, H. K., Gross, J. J., \& Dweck, S. C. (2011). Promoting the peace process by changing beliefs about group malleability. Science, 333 (1767).

Hall, N. R., \& Crisp, R. J. (2008). Assimilation and contrast to group primes: The moderating role of ingroup identification. Journal of Experimental Social Psychology, 44, 344-353.

Harwood, J. (2010). The contact space: A novel framework for intergroup contact research. Journal of Language and Social Psychology, 29, 147-177.

Harwood, J., Hewstone, M., Paolini, S., \& Voci, A. (2005). Grandparent-grandchild contact and attitudes toward older adults: Moderator and mediator effects. Personality and Social Psychology Bulletin, 31, 393-406.

Harwood, J., Paolini, S., Joyce, N., Rubin, M., \& Arroyo, A. (2010). Secondary transfer effects from imagined contact: Group similarity affects the generalization gradient. British Journal of Social Psychology, 50, 180-189.

Hayashi, N., Ostrom, E., Walker, J., \& Yamagishi, T. (1999). Reciprocity, trust, and the Sense of Control: A cross-societal study. Rationality and Society, 11, 27-46. 
Hebl, M. R., Tickle, J., \& Heatherton, T. F. (2000). Awkward moments in interactions between nonstigmatized and stigmatized individuals. In T. F. Heatherton, R. E. Kleck, M. R. Hebl, \& J. G. Hull (Eds.), The social psychology of stigma (pp. 275-306). New York, NY: Guilford Press.

Hewstone, M. (1994). Revision and change of stereotypic beliefs: In search of the elusive subtyping model. In W. Stroebe \& M. Hewstone (Eds.), European review of social psychology (Vol. 5, p. 69-109). London, UK; Wiley.

Hewstone, M., \& Brown, R. (1986). Contact is not enough: An intergroup perspective on the 'contact hypothesis'. In M. Hewstone and R. Brown (Eds.). Contact and conflict in intergroup encounters (pp. 1-44). Oxford, England: Blackwell.

Hodson, G., Choma, B. L., \& Costello, K. (2009). Experiencing alien-nation: Effects of a simulation intervention on attitudes toward homosexuals. Journal of Experimental Social Psychology, 45, 974-978.

Hodson, G., Harry, H., \& Mitchell, A. (2009). Independent benefits of contact and friendship on attitudes toward homosexuals among authoritarians and highly identified heterosexuals. European Journal of Social Psychology, 35, 509-525.

Hodson, G., \& Hewstone, M. (Eds.) (in press). Advances in Intergroup Contact. Psychology Press (Taylor \& Francis).

Hornsey, M. J., \& Hogg, M. A. (2000). Subgroup relations: A comparison of mutual intergroup differentiation and common ingroup identity models of prejudice reduction. Personality and Social Psychology Bulletin, 26, 242-256.

Husnu, S. \& Crisp, R. J. (2010a). Elaboration enhances the imagined contact effect. Journal of Experimental Social Psychology, 46, 943-950 
Husnu, S. \& Crisp, R. J. (2010b). Imagined intergroup contact: A new technique for encouraging greater inter-ethnic contact in Cyprus. Peace \& Conflict: Journal of Peace Psychology, 16, 97-108.

Husnu, S. \& Crisp, R. J. (2011). Enhancing the imagined contact effect. Journal of Social Psychology, 151, 113-116.

Islam, M., \& Hewstone, M. (1993). Intergroup attributions and affective consequences in majority and minority groups. Journal of Personality and Social Psychology, 64, 936-950.

James, W. (1890). The Principles of Psychology (Vol. 2).New York: Dover Publications Inc.

Jones, M. V., Mace, R. D., Bray, S. R., MacRae, A. W., \& Stockbridge, C. (2002). The impact of motivational imagery on the emotional state and self-efficacy levels of novice climbers, Journal of Sport Behaviour, 25, 57-73.

Kahneman, D., \& Tversky, A. (1982). The simulation heuristic, In D. Kahneman, P. Slovic and A. Tversky (Eds.) Judgement under uncertainty: Heuristics and biases (pp. 201-208). New York: Cambridge University Press.

Knudstrup, M., Segrest, S. L., \& Hurley, A. E. (2003). The use of mental imagery in the simulated employment interview situation. Journal of Managerial Psychology, 18, 575591.

Koeller, S. (1977). The effect of listening to excerpts from children's stories about MexicanAmericans on the attitudes of sixth graders. Journal of Educational Research, 70, 329334.

Kosslyn, S.M., Ganis, G. \& Thompson, W. L. (2001). Neural foundations of imagery. Nature Reviews Neuroscience, 2, 635-642. 
Landau, J.D., Libkuman, T.M., \& Wildman, J.C. (2002). Mental simulation inflates performance estimates for physical abilities. Memory \& Cognition, 30, 372379.

Lee, Y-T., \& Jussim, L. (2010). Back in the real world. American Psychologist, 65, 130-131.

Lessing, E. E., \& Clarke, C. C. (1976). An attempt to reduce ethnic prejudice and assess its correlates in a junior high school sample. Educational Research Quarterly, 1, 3-16.

Lewicki, R. J., McAllister, D. J., \& Bies, R. J. (1998). Trust and distrust: New relationships and realities. Academy of Management Review, 23, 438-458.

Levin, S., van Laar, C., \& Sidanius, J. (2003). The effects of ingroup and outgroup friendships on ethnic attitudes in college: A longitudinal study. Group Processes and Intergroup Relations, 6, 76-92.

Libby, L. K. \& Eibach, R. P. (2011). Visual perspective in mental imagery: An integrative model explaining its function in judgment, emotion, and self-insight. In M. P. Zanna \& J. Olson (Eds.). Advances in Experimental Social Psychology (vol. 45, pp. 185-254). Orlando, FL: Academic Press.

Libby, L. K., Shaeffer, E. M., Eibach, R. P., \& Slemmer, J. A. (2007). Picture Yourself at the Polls: Visual Perspective in Mental Imagery Affects Self-Perception and Behavior. Psychological Science, 18, 199-203

Mackie, D. M., Devos, T., \& Smith, E. R. (2000). Intergroup emotions: Explaining offensive action tendencies in an intergroup context. Journal of Personality and Social Psychology, $79,602-616$.

Marks, D.F. (1999). Consciousness, mental imagery and action. British Journal of Psychology, $90,567-585$. 
Marx, E., Deutschländer, A., Stephan, T., Dieterich, M., Wiesmann, M., \& Brandt, T. (2004). Eyes open and eyes closed as rest conditions: impact on brain activation patterns. NeuroImage, 21, 1818-1824.

Marx, E., Stephan, T., Nolte, A., Deutschländer, A., Seelos, K. C., Dieterich, M., \& Brandt, T. (2003). Eye closure in darkness animates sensory systems. NeuroImage, 19, 924-934.

McConnell, A. R., \& Leibold, J. M. (2001). Relations among the implicit association test, discriminatory behaviour, and explicit measures of racial attitude. Journal of Experimental Social Psychology, 37, 435-442.

McKelvie, S. J. (1995). The VVIQ and beyond: Vividness and its measurement. Journal of Mental Imagery, 19, 197-252.

Mummendey, A., Klink, A., \& Brown, R. (2001). A rejoinder to our critics and some of their misapprehensions. British Journal of Social Psychology, 40 187-191.

Narchal, R., \& Broota, K. D. (1988). Sex differences in vividness of visual imagery under eyes open and eyes closed conditions. Journal of Mental Imagery, 12, 81-88.

Oskamp, S., \& Jones, J. M. (2000). Promising practice in reducing prejudice: A report from the President's Initiative on Race. In S. Oskamp (Ed.), Reducing prejudice and discrimination (pp. 319-334). Mahwah, NJ: Lawrence Erlbaum.

Page-Gould, E., Mendoza-Denton, R., \& Tropp, L. R. (2008). With a little help from my crossgroup friend: Reducing anxiety in intergroup contexts through cross-group friendship. Journal of Personality and Social Psychology, 95, 1080 - 1094.

Paolini, S., Hewstone, M., Cairns, E., \& Voci, A. (2004). Effects of direct and indirect crossgroup friendships on judgements of Catholic and Protestants in Northern Ireland: The 
mediating role of an anxiety-reduction mechanism. Personality and Social Psychology Bulletin, 30, 770-786.

Pettigrew, T. F. (1997). Generalized intergroup contact effects on prejudice. Personality and Social Psychology Bulletin, 23, 173-185.

Pettigrew, T. F. (1998). Intergroup contact: Theory, research and new perspectives. Annual Review of Psychology, 49, 65-85.

Pettigrew, T. F. (2009). Secondary transfer effect of contact: Do intergroup contact effects spread to noncontacted outgroups? Social Psychology, 40, 55-65.

Pettigrew, T. F., \& Tropp, L. R. (2006). A meta-analytic test of intergroup contact theory. Journal of Personality and Social Psychology, 90, 751-783.

Pettigrew, T. F., \& Tropp, L. R. (2008). How does intergroup contact reduce prejudice? Metaanalytic test of three mediators. European Journal of Social Psychology, 38, 922-934.

Petty, R. E., \& Mirels, H. L. (1981). Intimacy and scarcity of self-disclosure: Effects on interpersonal attraction for males and females. Personality and Social Psychology Bulletin, 7, 493-503.

Pham, L. B., \& Taylor, S. E. (1999). From thought to action: Effects of process-versus outcomebased mental simulations on performance. Personality and Social Psychology Bulletin, 25, 250-260.

Piaget, J. (1970). Piaget's theory. In P. H. Mussen (Ed.), Carmichael's manual of child psychology (pp. 703-732.) New York: Wiley.

Plant, E. A., \& Devine, P. G. (2003). The antecedents and implications of interracial anxiety. Personality and Social Psychology Bulletin, 29, 790-801. 
Preston, S. D., \& de Waal, F. B. M. (2002). Empathy: Its ultimate and proximate bases, Behavioral and Brain Sciences, 25, 1-20.

Randi, J., \& Corno, L. (2000). Teacher innovations in self-regulated learning. In M. Boekaerts, P. Pintrich, \& M. Zeidner (Eds.), Handbook of Self-regulation (pp. 651-685). New York, NY:Academic Press.

Ratcliff, C. D., Czuchry, M., Scarberry, N. C., Thomas, J. C., Dansereau, D. F., \& Lord, C. G. (1999). Effects of directed thinking on intentions to engage in beneficial activities: actions versus reasons. Journal of Applied Psychology, 29, 994-1009.

Raune, D., MacLeod, A., \& Holmes, E. (2005). The simulation heuristic and visual imagery in pessimism for future negative events in anxiety. Clinical Psychology and Psychotherapy, $12,313-325$.

Rivkin, I. D., \& Taylor, S. E. (1999). The effects of mental simulation on coping with controllable stressful events. Personality and Social Psychology Bulletin, 25, 1451-1462.

Robbins, J., M., \& Krueger, J. I. (2005). Social projection to ingroups and to outgroups: A review and meta-analysis. Personality and Social Psychology Review, 9, 32-47.

Roese, N. J., \& Olson, J. M. (1996). Counterfactuals, causal attributions, and the hindsight bias: A conceptual integration. Journal of Experimental Social Psychology, 32, 197-227.

Ross, L., Lepper, M. R. \& Hubbard, M. (1975). Perseverance in self-perception and social perception: Biased attributional processes in the debriefing paradigm. Journal of Personality and Social Psychology, 32, 880-892.

Sanna, L. J., Carter, S. E., \& Burkley, E. (2005). Yesterday, today, and tomorrow: Counterfactual thinking and beyond. In A. J. Strathman \& J. A. Joireman (Eds.), Understanding behavior in the context of time: Theory, research, and application (pp. 165- 
185). Mahwah, NJ: Erlbaum

Schank, R. C., \& Abelson, R. P. (1977). Scripts, plans, goals, and un-derstanding. Hillsdale, N.J. Erlbaum

Schulze, B., Richter-Werling, M., Matschinger, H. \& Angermeyer, M. C. (2003). Crazy? So what! Effects of a school project on students' attitudes towards people with schizophrenia. Acta Psychiatrica Scandinavica, 107, 142-150.

Sears, D. O. (1983). The person-positivity bias. Journal of Personality and Social Psychology, $44,233-250$.

Sherman, S. J., Cialdini, R. B., Schwartzman, D. F. \& Reynolds, K. D. (1985). Imagining can heighten or lower the perceived likelihood of contracting a disease: The mediating effect of ease of imagery. Personality and Social Psychology Bulletin, 11, 118-127.

Sherman, S. J., \& Anderson, C. A. (1987). Decreasing premature termination from psychotherapy. Journal of Social and Clinical Psychology, 5, 298-312.

Shelton, J. N., \& Richeson, J. A. (2005). Intergroup contact and pluralistic ignorance. Journal of Personality and Social Psychology, 88, 91-107.

Sidanius, J., \& Pratto, F. (2001). Social Dominance: An Intergroup Theory of Social Hierarchy and Oppression. Cambridge: Cambridge University Press.

Simon, B., \& Brown, R. (1987). Perceived intragroup homogeneity in minority-majority contexts. Journal of Personality and Social Psychology, 53, 703-711.

Sleeter, C. E., \& Grant, C. A. (1994). Making choices for multi-cultural education. New York: Macmillan. 
Spencer, S. J., Zanna, M. P., \& Fong, G. T. (2005). Establishing a causal chain: Why experiments are often more effective than mediational analyses in examining psychological processes. Journal of Personality and Social Psychology, 89(6), 845-851.

Stangor, C., Sullivan, L. A., \& Ford, T. E. (1991). Affective and cognitive determinants of prejudice. Social Cognition, 9, 359-380.

Stathi, S. \& Crisp, R. J. (2008). Imagining intergroup contact promotes projection to outgroups. Journal of Experimental Social Psychology, 44, 943-957.

Stathi, S., Crisp, R. J., \& Hogg, M. A. (2011). Imagining intergroup contact enables member-togroup generalization. Group Dynamics: Theory, Research \& Practice, 15, 275-284.

Stephan, W. G., \& Stephan, C. W. (1985). Intergroup anxiety. Journal of Social Issues, 41, 157176.

Stephan, W. G., Diaz-Loving, R., \& Duran, A. (2000). Integrated threat theory and intercultural attitudes: Mexico and the United States. Journal of Cross-Cultural Psychology, 31, 240249.

Stone, C. H., \& Crisp, R. J. (2007). Superordinate and subgroup identification as predictors of intergroup evaluation in common ingroup contexts. Group Processes \& Intergroup Relations, 10, 493-513.

Stroop, J. R. (1935). Studies of interference in serial verbal reactions. Journal of Experimental Psychology, 18, 643-662.

Swart, H., Hewstone, M., Christ, O., \& Voci, A. (2011). Affective mediators of intergroup contact: A three-wave longitudinal study in South Africa. Journal of Personality and Social Psychology. 
Tam, T., Hewstone, M., Harwood, J., Voci, A., \& Kenworthy, J. (2006). Intergroup contact and grandparent-grandchild communication: The effect of self-disclosure on implicit and explicit biases against older people. Group Processes and Intergroup Relations, 9, 413429.

Tam, T., Hewstone, M., Kenworthy, J., Cairns, E. (2009). Intergroup trust in Northern Ireland. Personality and Social Psychology Bulletin, 35, 45-59.

Tausch, N., Hewstone, M., Schmidt, K., Hughes, J., \& Cairns, E. (2011). Extended contact effects as a function of closeness of relationship with ingroup contacts. Group Processes \& Intergroup Relations, 14, 239-254.

Taylor, S. E., Pham, L.B., Rivkin, I. D. \& Armor, D. A. (1998). Harnessing the imagination: mental simulation, self-regulation, and coping. American Psychologist, 53, 429-39.

Ten Eyck, L. L., Labansat, H. A., Gresky, D. M., Dansereau, D. F., Lord, C. G. (2006). Effects of directed thinking on intentions to engage in beneficial activities: Idea generation or mental simulation? Journal of Applied Social Psychology, 36, 1234-1262.

Tropp, L. R. (2003). The psychological impact of prejudice: Implications for intergroup contact. Group Processes \& Intergroup Relations, 6, 131-149.

Turner, R. N. \& Crisp, R. J. (2010a). Explaining the relationship between ingroup identification and intergroup bias following recategorization: A self-regulation theory analysis. Group Processes and Intergroup Relations, 13, 251-261.

Turner, R. N., \& Crisp, R. J. (2010b). Imagining intergroup contact reduces implicit prejudice. British Journal of Social Psychology, 49, 129-142.

Turner, R. N., Crisp, R. J., \& Lambert, E. (2007a). Imagining intergroup contact can improve intergroup attitudes. Group Processes and Intergroup Relations, 10, 427-441. 
Turner, R. N., \& Feddes, A. (in press). How intergroup friendship works: A longitudinal study of friendship effects on outgroup attitudes. European Journal of Social Psychology.

Turner, R. N., Hewstone, M., \& Voci, A. (2007a). Reducing explicit and implicit prejudice via direct and extended contact: The mediating role of self-disclosure and intergroup anxiety. Journal of Personality and Social Psychology, 93, 369-388

Turner, R. N., Hewstone, M., Voci, A., \& Vonofakou, C. (2008). A test of the extended intergroup contact hypothesis: The mediating role of intergroup anxiety, perceived ingroup and outgroup norms, and inclusion of the outgroup in the self. Journal of Personality and Social Psychology, 95, 843-860.

Turner, R. N., Hewstone, M., Voci, A., Paolini, S., \& Christ, O. (2007b). Reducing prejudice via direct and extended cross-group friendship. European Review of Social Psychology, 18, 212-255.

Turner, R. N., \& West, K. (in press). Behavioural consequences of imagining intergroup contact with stigmatized outgroups. Group Processes and Intergroup Relations.

Turner, R. N., West, K., \& Christie, Z. (in press). Outgroup trust, intergroup anxiety, and outgroup attitude as mediators of the effect of imagined intergroup contact on intergroup behavioural tendencies. Journal of Applied Social Psychology.

Turner, R. N., Wildschut, R. T., \& Sedikides, C. (in press). Dropping the weight stigma: Nostalgia improves attitudes toward persons who are overweight. Journal of Experimental Social Psychology

Tversky, A., \& Kahneman, D. (1973). Availability: A heuristic for judging frequency and probability. Cognitive Psychology, 5, 207-232. 
Vasquez, N. A., \& Buehler, R. (2007). Seeing future suc- cess: Does imagery perspective influence achieve- ment motivation. Personality and Social Psychology Bulletin, 33, 13921405.

Vezzali, L., Capozza, D., Giovannini, D. \& Stathi, S. (in press-a). Improving implicit and explicit intergroup attitudes using imagined contact: An experimental intervention with elementary school children. Group Processes and Intergroup Relations.

Vezzali, L., Capozza, D., Stathi, S. \& Giovannini, D. (in press-b). Increasing Outgroup Trust, Reducing Infrahumanization, and Enhancing Future Contact Intentions via Imagined Intergroup Contact. Journal of Experimental Social Psychology.

Voci, A., \& Hewstone, M. (2003). Intergroup contact and prejudice towards immigrants in Italy: The mediational role of anxiety and the moderational role of group salience. Group Processes and Intergroup Relations, 6, 37-54.

Wagner, U., van Dick, R., Pettigrew, T. F., \& Christ, O. (2003). Ethnic prejudice in East and West Germany: The explanatory power of intergroup contact. Group Processes and Intergroup Relations, 6, 22-36.

Weber R., \& Crocker, J. (1983). Cognitive processes in the revision of stereotypic beliefs. Journal of Personality and Social Psychology, 45, 961-977.

West, K., Holmes, E., \& Hewstone, M. (2011). Enhancing imagined contact to reduce prejudice against people with schizophrenia.Group Processes \& Intergroup Relations, 14, 407-428.

Wilder, D. A. (1984). Intergroup contact: The typical member and the exception to the rule. Journal of Experimental Social Psychology, 20, 177-194. 
Wolsko, C., Park, B., Judd, C. M., \& Bachelor, J. (2003). Intergroup contact: Effects on group evaluations and perceived variability. Group Processes and Intergroup Relations, 6, 93110.

Wilson, T. D., \& Capitman, J. A. (1982). Effects of script availability on social behaviour. Personality and Social Psychology Bulletin, 8, 11-19.

Wright, S. C., Aron, A., McLaughlin-Volpe, T., \& Ropp, S. A. (1997). The extended contact effect: Knowledge of cross-group friendships and prejudice. Journal of Personality and Social Psychology, 73, 73-90. 
Table 1. Imagined contact effects on attitudes, evaluations and perceived group variabilility (Turner, Crisp, \& Lambert, 2007).

Task

\begin{tabular}{lcc}
\hline & Control & Imagined Contact \\
\hline Intergroup bias (Experiment 1) & $1.14(1.66)$ & $-1.00(3.40)$ \\
Intergroup bias (Experiment 2) & $1.82(1.23)$ & $-.87(1.49)$ \\
Outgroup evaluation (Experiment 3) & $3.02(1.46)$ & $3.82(1.86)$ \\
Outgroup variability (Experiment 3) & $3.97(.86)$ & $4.64(1.23)$ \\
\hline
\end{tabular}

NOTE:

Standard deviations are shown in parentheses

Positive intergroup bias score denotes preference for ingroup over outgroup, whereas a negative intergroup bias score reflects preference for outgroup over ingroup

All differences significant at $\mathrm{p}<.05$ 
Table 2. IAT-D scores (Turner \& Crisp, 2010).

Task

\begin{tabular}{lcc}
\hline & Control & Imagined Contact \\
\hline Implicit age bias (Experiment 1) & $0.87(.34)$ & $0.46(.37)$ \\
Implicit religion bias (Experiment 2) & $0.49(24)$ & $-.63(.49)$ \\
\hline
\end{tabular}

NOTE:

Standard deviations are shown in parentheses

A positive D-score indicates an implicit preference for ingroup over outgroup

All differences significant at $\mathrm{p}<.05$ 
Table 3. Imagined contact effects on social distance behavior (Turner \& West, in press).

Task

Control Imagined Contact

\begin{tabular}{lll}
\hline Chair distance in cm (Experiment 1) & $50.14(15.29)$ & $40.10(19.29)$ \\
Chair distance in cm (Experiment 2) & $89.85(14.13)$ & $73.52(24.89)$
\end{tabular}

NOTE:

Standard deviations are shown in parentheses

All differences significant at $\mathrm{p}<.05$ 
Table 4: Future contact intentions as a function of imagined contact and visual perspective (Crisp \& Husnu, 2010)

Task

\begin{tabular}{lcc}
\hline & Control & Imagined Contact \\
\hline $1^{\text {st }}$ Person & $5.71(1.06)$ & $6.22(1.33)$ \\
$3^{\text {rd }}$ Person & $5.99(1.27)$ & $7.04(1.17)$ \\
\hline
\end{tabular}



Figure 1: Antecedents, processes and outcomes of imagined intergroup contact.

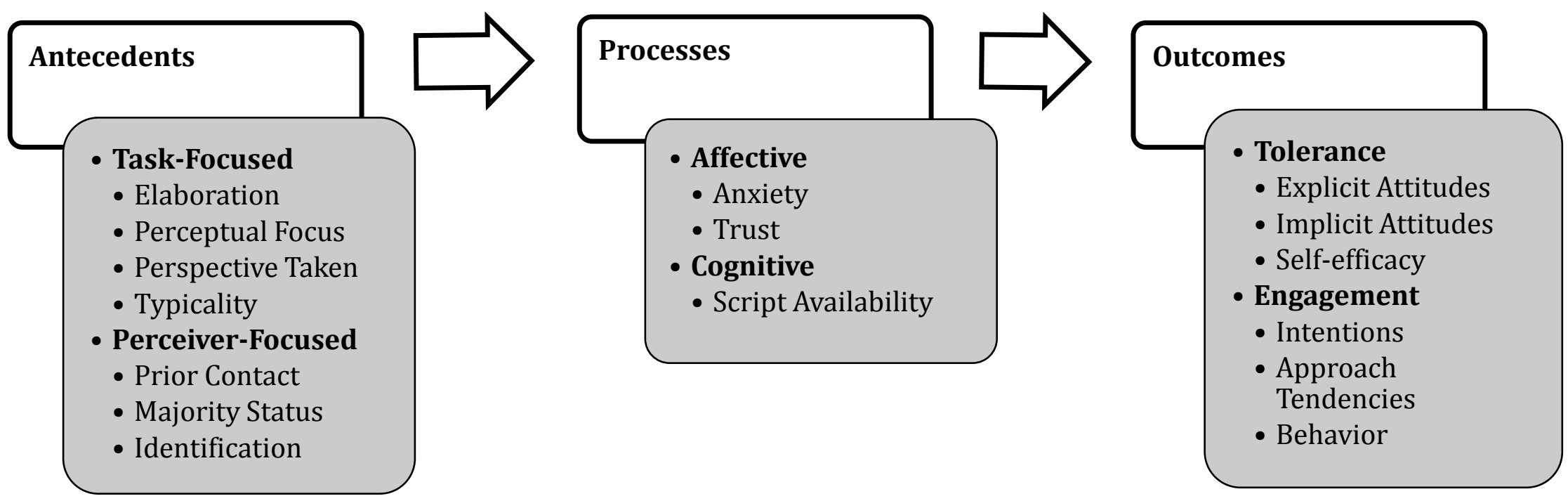


Figure 2: Approach and avoidance tendencies following imagined contact (Turner, West, \& Christie, in press; Experiment 2).

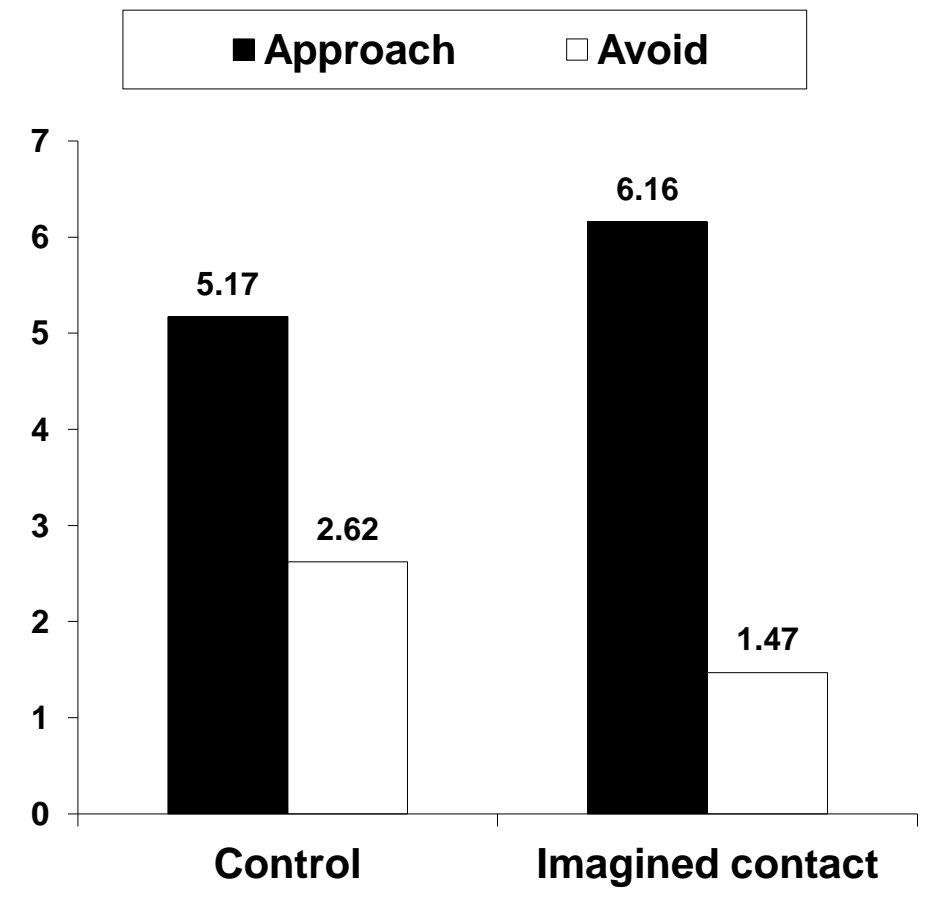


Figure 3: Imagined contact effects on attitudes and beliefs about the outgroup (Turner \& West, in press, Experiment 2).
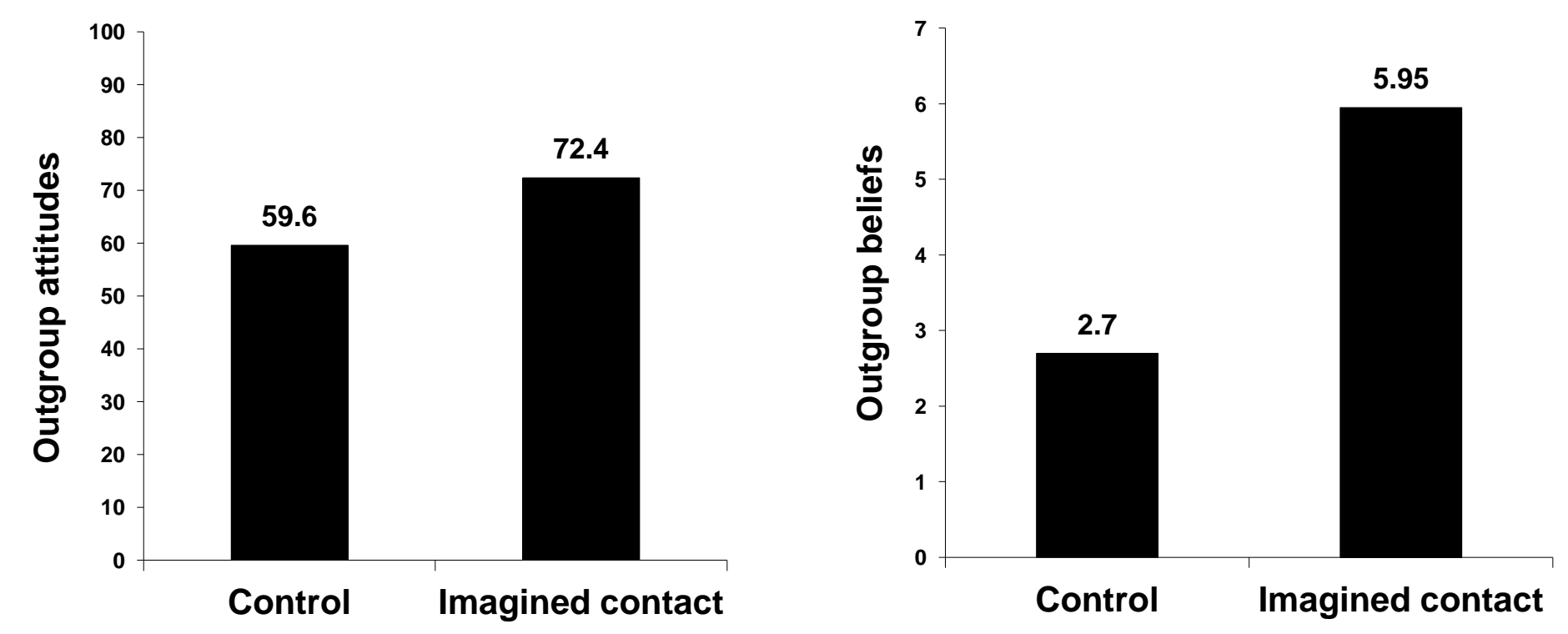


\section{Figure 4:}

Mediational model of the role of intergroup anxiety in explaining the effects of imagined contact on outgroup evaluation. Turner, Crisp, \& Lambert (Experiment 3,2007$) . * p<.05 ; * * p<.01 ; * * * p<.001$

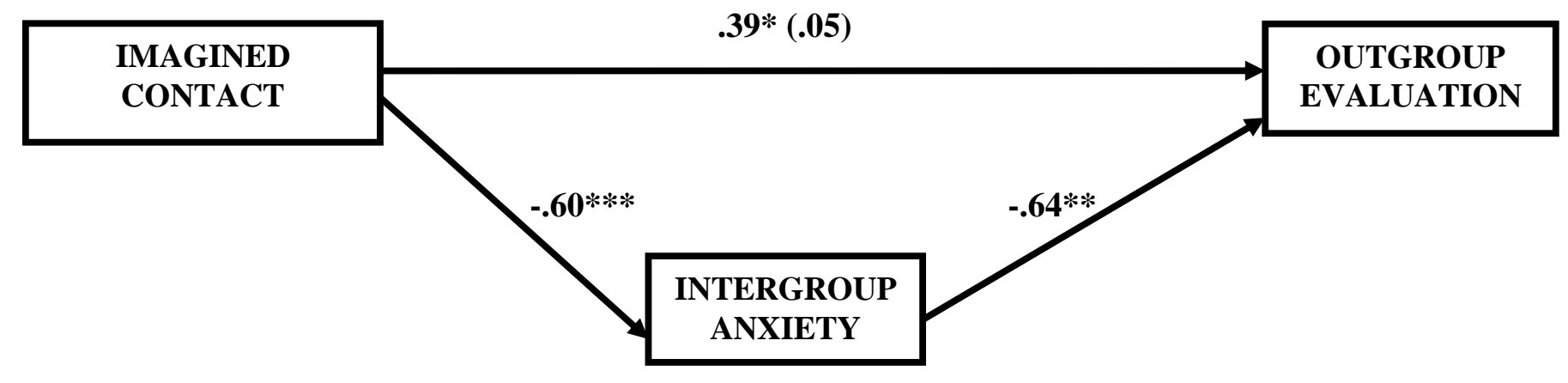


Figure 5: Path model showing intergroup anxiety, outgroup trust, and outgroup attitude as mediators of the relationship between imagined contact and approach and avoid behavioural tendencies (Turner, West, \& Christie, in press; Experiment 2).

$* p<.05 ; * * p<.01 ; * * * p<.001 ; N=41$. Standardized coefficients, only significant paths are reported. Correlations: intergroup anxiety outgroup trust: $r=-.46, p=.008$; intergroup anxiety - outgroup attitude: $r=-.41, p=.016$; outgroup trust - outgroup attitude: $r=.54, p$ $=.003$; approach behavioural tendencies - avoid behavioural tendencies: $r=-.21, p=.20$.

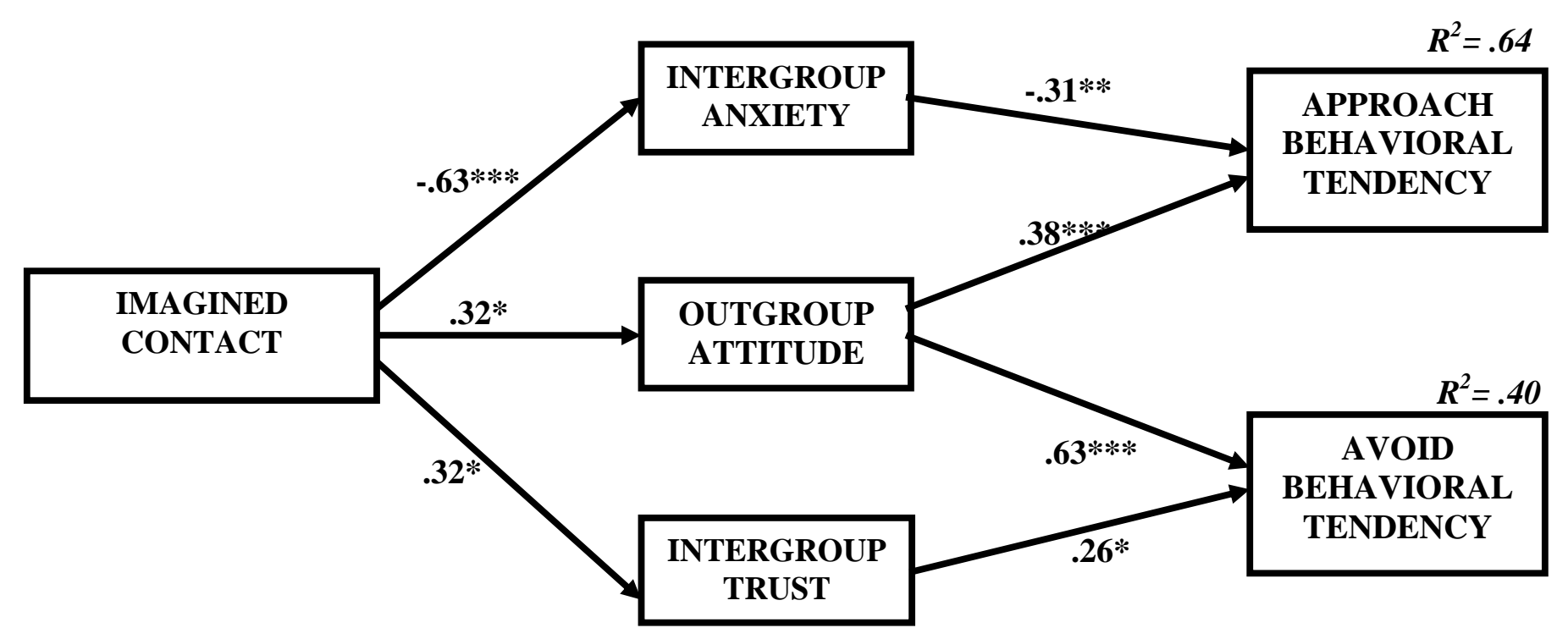


Figure 6: Elaborated imagined contact effects on likelihood of future contact estimates (Husnu \& Crisp, in press, Experiment 2).

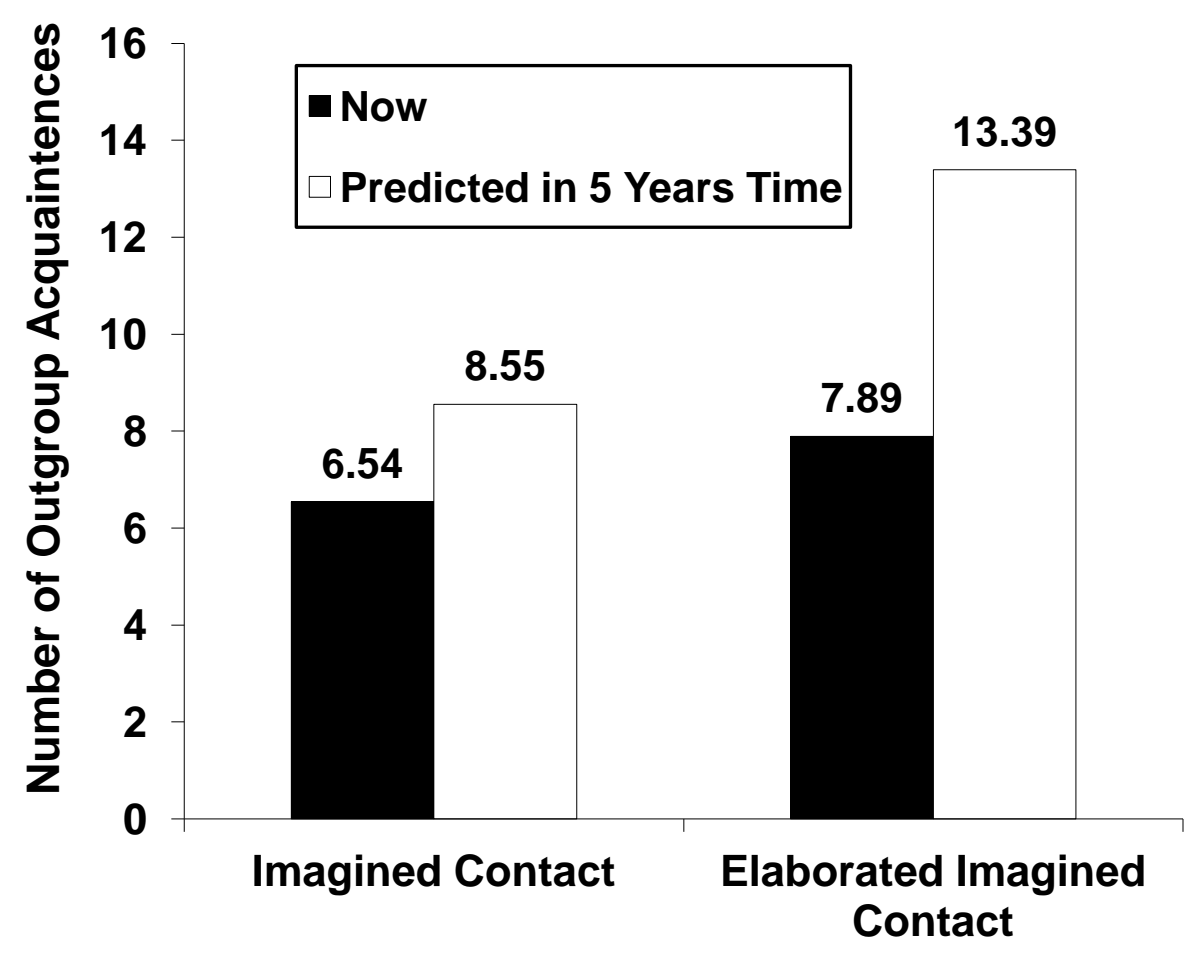


Figure 7: Mediational model of the role of vividness in explaining the effects of elaborated imagined contact on future contact intentions. Based on data from Husnu \& Crisp (2010a, Experiment 2). * $p<.05 ; * * p<.01 ; * * *<.001$

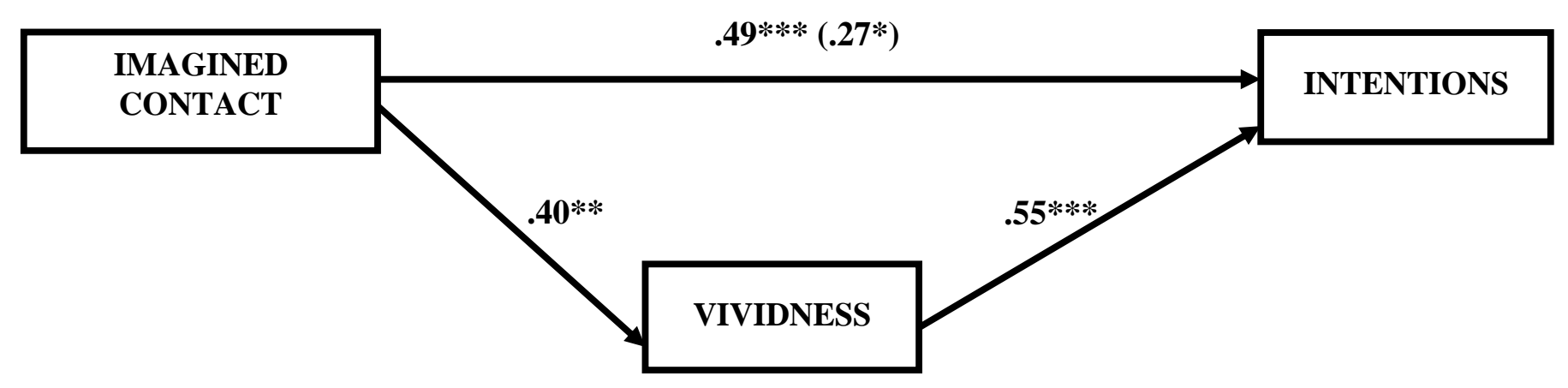


Figure 8: Effects of imagined contact on intergroup outcomes for primary school children (Cameron et al., in press).

\section{- Attitude $\square$ Warmth $\square$ Competence $\square$ Intended behaviour}

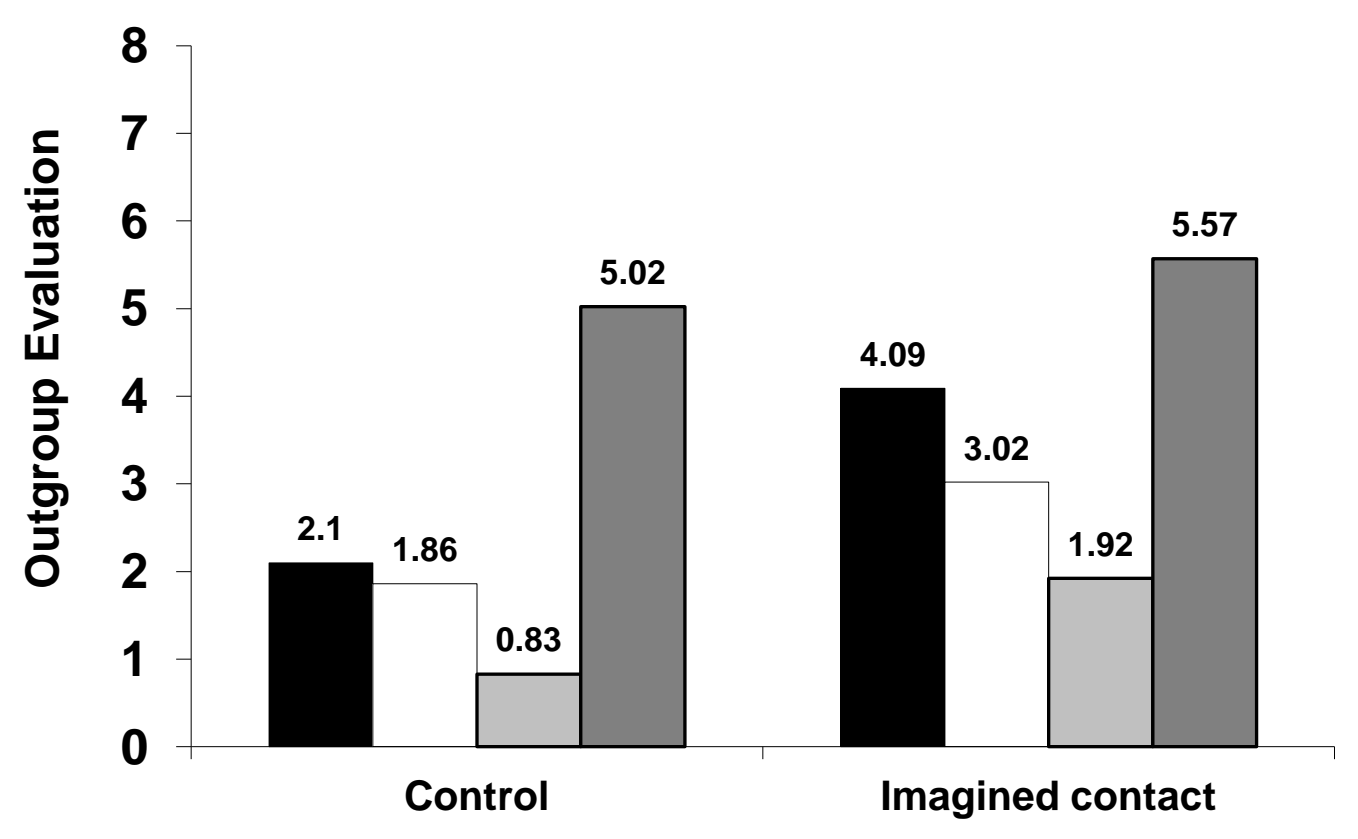

